OPEN ACCESS

Edited by:

Hugh Thomson Reyburn, Consejo Superior de Investigaciones

Científicas (CSIC), Spain

Reviewed by: Ana Stojanovic,

Heidelberg University, Germany Jiacheng Bi,

Chinese Academy of Sciences (CAS),

China

Camille Guillerey

University of Queensland, Australia

*Correspondence:

Jeak Ling Ding

dbsdj@@us.edu.sg

${ }^{t}$ These authors share first authorship

Specialty section:

This article was submitted to

NK and Innate Lymphoid Cell Biology,

a section of the journal

Frontiers in Immunology

Received: 01 July 2021

Accepted: 30 August 2021

Published: 14 September 2021

Citation:

Lee EHC, Wong DCP and Ding JL (2021) NK Cells in a Tug-of-War With

Cancer: The Roles of Transcription

Factors and Cytoskeleton.

Front. Immunol. 12:734551.

doi: 10.3389/fimmu.2021.734551

\section{NK Cells in a Tug-of-War With Cancer: The Roles of Transcription Factors and Cytoskeleton}

\author{
E Hui Clarissa Lee ${ }^{\dagger}$, Darren Chen Pei Wong ${ }^{\dagger}$ and Jeak Ling Ding * \\ Department of Biological Sciences, National University of Singapore, Singapore, Singapore
}

Natural killer (NK) cells are innate immune cells which play a key role in shaping the immune response against cancer. Initially hailed for their potential to recognise and eliminate tumour cells, their application has been greatly hindered by the immunosuppressive tumour microenvironment (TME) which suppresses NK functions (e.g., cytotoxicity). This dysfunctional state that is accompanied by phenotypic changes such as upregulation of inhibitory receptors and downregulation of activating receptors, forms the basis of what many researchers have referred to as 'exhausted' NK cells. However, there is no consensus on whether these phenotypes are sufficient to define an exhausted state of the NK cell. While recent advances in checkpoint inhibition appear to show promise in early-stage pre-clinical studies, much remains to be fully explored and understood in the context of the TME. The TME is where the NK cells are subjected to interaction with various cell types and soluble factors, which could exert an inhibitory effect on NK cytotoxicity. In this review, we provide an overview of the general markers of NK cell exhaustion viz, the surface activating and inhibitory receptors. We also highlight the potential role of T-box transcription factors in characterising such a dysfunctional state and discuss the often-overlooked mechanism of cell cytoskeletal dynamics in regulating NK cell function. These aspects may further contribute to NK exhaustion or NK revival in cancer and may open new avenues to explore cancer treatment strategies.

Keywords: natural killer cells (NK), cancer, tumour microenvironment (TME), NK exhaustion, NK cell receptors, T-box transcription factors, cytoskeletal dynamics, mechanotransduction

\section{INTRODUCTION}

Natural killer cells (NK) belong to the family of Group 1 Innate Lymphoid Cells (ILC), and have been well-characterised for their cytotoxic functions against a wide variety of pathogens, infections and cancers (1).

Distinct from the adaptive immune cells, NK cells are purported to recognise target cells without prior antigen sensitisation (2). Instead, classical schools of thought imply that NK cell activation depends heavily on the functional state and balance of surface activating and inhibitory receptors (2), which recognise stress-induced ligands or detect a 'missing self', characterised by the lack of MHC class I molecules on cancer cells or infected cells (1). These characteristics make NK cells an attractive immune sentinel for cancer immunomodulation, especially in view of the shortfalls in immunotherapy, which has thus far been largely focused on CAR-T and immune checkpoint inhibition 
(ICI) targeting T cells. Some of these limitations in $\mathrm{T}$ cell based therapy include acquired mutations in antigen presentation genes with subsequent loss of antigen presentation machinery (3), and the heterogeneous nature of cancers resulting in patient non-response or relapse (4). These issues have undermined the long-term efficacy of $\mathrm{T}$ cell-mediated cancer therapy and have triggered interest in exploring NK cells as a complementary, or potentially a more efficacious therapeutic option.

Despite the promising potential of NK cells, clinical trials utilizing NK cell immunotherapy have thus far yielded limited outcomes. With traditional adoptive transfer either from an allogeneic or autologous source, NK cells were observed to quickly lose their function in vivo (5), exhibiting what has been deemed an exhausted phenotype. This has prompted a paradigm shift in exploring strategies for restoring and sustaining NK cell functions, such as checkpoint blockade or the genetic engineering of NK cells to express exogenous activating receptors. Recent trends to investigate novel and practical ways to reverse NK cell dysfunction are anticipated to provide substantial understanding of how cancer suppresses and sustains the loss of NK cell activity.

While the dysfunctional NK cells observed in cancer patients have been described by various groups as having an 'exhausted' phenotype, it is worth noting that the concept of NK cell exhaustion remains unclear. Thus far, NK cell exhaustion is commonly used to refer to NK cells exhibiting reduced effector function as well as up- and down-regulation of various activating and inhibitory surface receptors, respectively. In this review, we adopt these phenotypic changes and accompanying functional impairment to be the basis of NK cell exhaustion, and we discuss how they contribute to exhaustion, and propose additional aspects that may provide a more complete picture of NK cell exhaustion. We also summarise the roles of numerous players in the tumour microenvironment (TME) which contribute to the dysfunctional state of NK cells. Importantly, various overlooked mechanisms of NK cell regulation are highlighted.

\section{CHARACTERISTICS OF DYSFUNCTIONAL/EXHAUSTED NK CELLS IN CANCER}

Functionally impaired NK cells have been observed across a wide range of solid tumours as well as haematological malignancies (6, 7 ) and often also show reduced infiltration into tumour sites (7, 8). Peripheral NK cells from cancer patients as well as tumourinfiltrating NK cells exhibit reduced effector functions such as (i) decreased expression of the membrane protein CD107a, which is a degranulation marker, (ii) decreased secretion of cytokines $\operatorname{IFN} \gamma(9,10)$ and TNF $\alpha(10)$, and the cytotoxic molecules, perforin (11) and granzyme (12), all of which result in reduced NK cell function against tumour cells. This loss of function in NK cells is often referred to as 'exhaustion', a phenomenon which was first observed in effector $\mathrm{T}$ cells present in persistent chronic infections and cancers $(13,14)$. Diminished effector function and accompanying phenotypic changes have been similarly observed in both exhausted T cells and NK cells. In contrast to T cell exhaustion, which is clearly defined both functionally and phenotypically (13), no strict consensus has thus far been established on what exactly constitutes an exhausted state of NK cells. This has prompted more than a decade of research on the characterisation of NK cell exhaustion.

In addition to the often observed functional impairment, numerous studies have also suggested the imbalance in the expression levels of NK cell surface activating and inhibitory receptors to be an indicator of exhaustion $(6,15-17)$. A diverse repertoire of activating and inhibitory receptors is expressed on the NK cell surface, and the balance and spatial-temporal integration of signals from these receptors have been established to impact NK cell effector function (18). Inhibitory receptors include the killer cell immunoglobin receptors (KIRs), CD94/ NKG2A and leukocyte immunoglobin-like receptors (LIRs), which typically function by recruitment of SHP-1/SHP-2, then inducing Vav1, LAT, and PLC $\gamma 1 / 2$ dephosphorylation and Crk phosphorylation, which in turn inhibit NK cell activation signals and hence its function (19). Major activating receptors include the natural cytotoxic receptors (NCRs), NKG2D and DNAM-1, whose activating signals are typically transmitted through receptors binding to ITAM-containing adaptor proteins such as DAP10, DAP12, and FcR $\gamma(19)$. Engagement of these NK surface receptors with their respective ligands thus results in the transduction of either activating or inhibitory signals through various signalling pathways, which eventually converge on key processes regulating $\mathrm{NK}$ cell cytotoxicity such as target cell conjugation, degranulation, and cytokine release (19).

Due to the sheer number of receptors present and many receptors sharing recognition of the same ligands, there is no consistent standard yet as to which of these receptors are specific and precise markers of exhaustion. However, it is clear that the altered expression of multiple receptors is key to characterising exhaustion: for example, activating receptors, with the exception of CD16, are not able to activate NK cells on their own (19). In the case of the inhibitory receptor TIGIT, it has also been reported that TIGIT expression levels on NK cell surface are variable even in healthy individuals (20). Although higher TIGIT expression on healthy human NK cells correlates with reduced cytotoxic potential (20), these NK cells still largely retain their function. Thus, the elevated expression of a particular inhibitory receptor or downregulation of a single activating receptor does not necessarily mark a severely dysfunctional NK cell state as is observed in the case of chronic infections and cancers. In other words, the altered expression of a single receptor is unlikely to significantly alter NK cell activation status, instead, multiple activating and/or inhibitory receptors have to be down- or upregulated, respectively, to result in NK cell exhaustion.

In the context of cancer, these receptors have been implicated as markers of NK cell exhaustion, as their dysregulated expression is often associated with reduced NK antitumour activity (Table 1). Upregulation of inhibitory receptors and downregulation of activating receptors typically correlates with reduced NK cell function as discussed above. Existing attempts have also been made at targeting these receptors (Table 1) for the reinvigoration of NK cell function. 
TABLE 1 | Archetypal NK receptors in NK cell function, exhaustion and restoration.

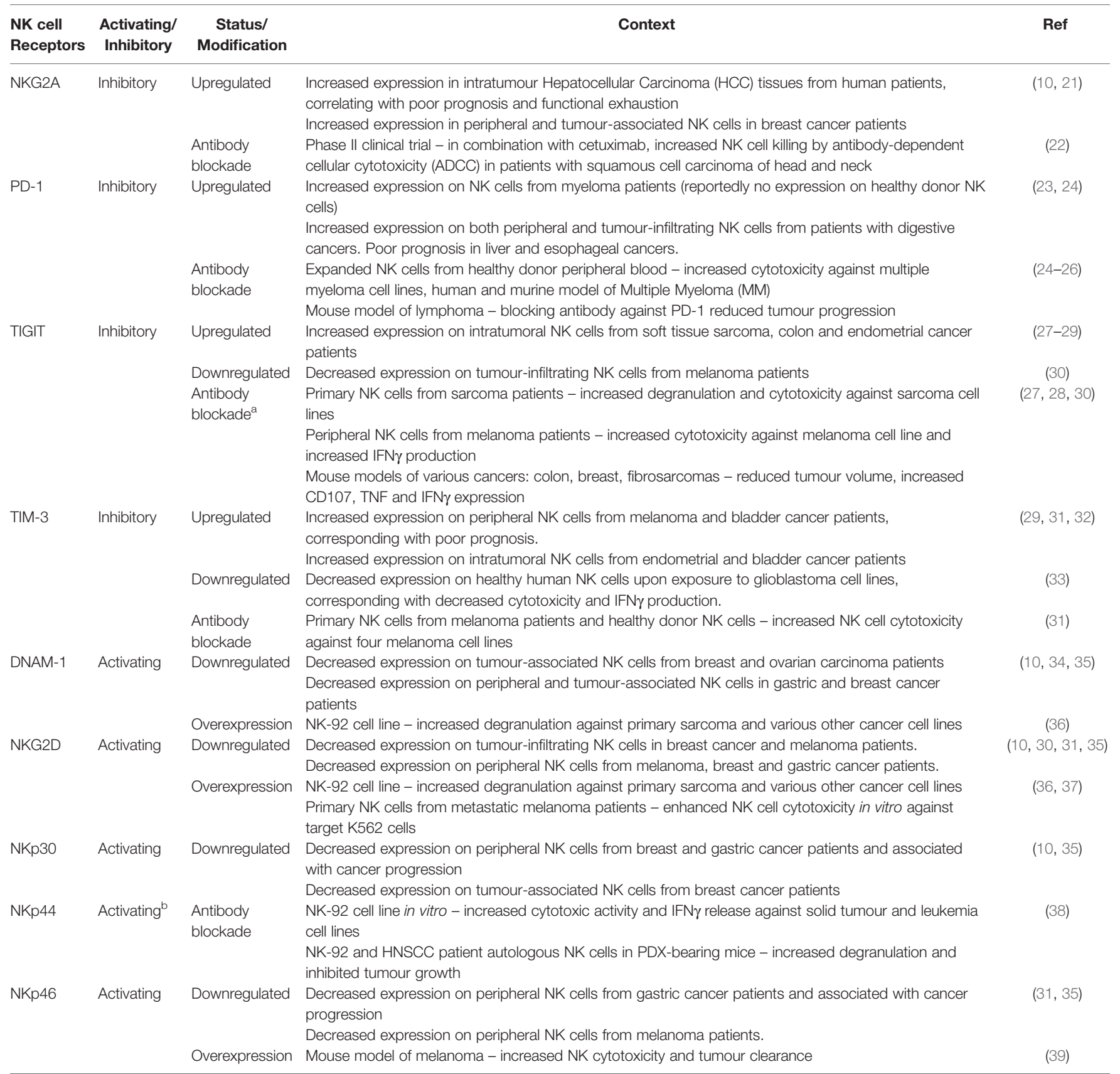

${ }^{a}$ TIGIT blockade alone increases IFN yproduction in circulating NK cells, but has to be used in combination with IL-15 to promote increased cytotoxicity in tumour infiltrating NK cells (30).

${ }^{b} \mathrm{NKp} 44$ is classified as an activating receptor, but can also have inhibitory effects when engaged with inhibitory ligands such as PCNA (40).

\section{ROLE OF T-BOX TRANSCRIPTION FACTORS IN CELL PHENOTYPE AND FUNCTION: PARALLELS IN NK AND T CELLS}

T-bet and Eomes are members of the T-box family of transcription factors which are characterised by the presence of a conserved Tbox DNA binding domain, and have been evolutionary entrenched since the early metazoans (41). They are the only members of the T-box transcription factors expressed in the immune system and are fundamental to the development and existence of NK cells (42). The expression of T-bet and Eomes are tightly regulated throughout the different stages of NK cell development (43-45), with the presence of both transcription factors being crucial for proper development. NK cells fail to develop in the absence of both transcription factors, and deletion of either T-bet or Eomes results in NK cells that are unable to reach full maturation (45). Their expression is also deemed to be 
crucial for mature NK cell cytotoxic function (42), with NK cells from Eomes knockout mice demonstrating reduced IFN $\gamma$ production, as well as Eomes ${ }^{+}$cells producing more perforin than Eomes ${ }^{-}$cells (45). T-bet has also been shown to bind to the promoters of perforin $(P R F)$, granzyme $\mathrm{B}(G Z M B)$ and IFN $\gamma$ (IFNG) (43), suggesting a role for T-bet in regulating NK cell cytotoxicity. Together, these studies suggest that changes in T-bet and Eomes expression and activity may potentially be a surrogate for NK cell dysfunction.

T-bet and Eomes are also key transcription factors in T cells, regulating both function and homeostasis $(46,47)$. They have both been demonstrated to be essential for effective $\mathrm{T}$ cell antitumour response (48), with dysregulation in expression levels being linked to an exhausted $\mathrm{T}$ cell phenotype in various contexts including infection and cancer $(49,50)$. Eomes expression in exhausted $\mathrm{T}$ cells correlates with severity of exhaustion during chronic viral infection, along with high inhibitory receptor expression (51). Additionally, Eomes ${ }^{+}$T-bet ${ }^{\text {low }}$ CD8 $\mathrm{T}$ cells exhibit functional impairment in leukaemia patients, partly attributable to Eomes binding to the promoter of the inhibitory receptor TIGIT and positively regulating its expression (52). Interestingly, a recent study reported that $\mathrm{T}$ cell exhaustion may not simply be defined by the overall T-bet and Eomes expression, but rather that high nuclear Eomes:T-bet ratio is key in defining $\mathrm{T}$ cell exhaustion in both chronic LCMV infection as well as in human melanoma patients (53). This provides further insights into the biology of how these T-box transcription factors regulate $\mathrm{T}$ cell exhaustion.

However, whether an altered balance of T-bet and Eomes affects NK cell function and exhaustion in cancer, and whether dysfunctional NK cells show a similar expression pattern of T-bet and Eomes compared to that of exhausted $\mathrm{T}$ cells, remain less clear. Circulating healthy human NK cells were reported to express high T-bet and low Eomes, and an intricate balance between T-bet and Eomes seems to characterise NK cell function (54). In the context of cancer, a study in 2012 reported a murine model of cancer where loss of NK effector functions was accompanied by a rapid downregulation of both T-bet and Eomes (55). In another study involving exhausted murine NK cells characterised by high expression of inhibitory receptors, TIM-3 and PD-1, reduced Eomes expression was similarly observed, although this was also accompanied by increased Tbet (56). Studies on melanoma patients showed that both T-bet and Eomes were downregulated in NK cells (31). However, in lung cancer patients, only reduced Eomes expression was found to correlate with cancer progression and NK cell dysfunction (57). Furthermore, overexpression of Eomes in NK cells (55) or adoptive transfer of Eomes ${ }^{\text {hi }} \mathrm{NK}$ cells (57) was able to reduce tumour burden in mice (55). These reports suggest that beyond NK cell surface receptor expression, altered expression of both Tbox transcription factors and their corresponding transcriptional programs also play a role in mediating $\mathrm{NK}$ cell cytotoxicity against cancer, and could be used to assess NK cell dysfunction. Although the role of T-bet in mediating NK cell function against cancer remains less clear, increased Eomes expression appears to be consistently implicated in improved antitumour activities of NK cells, both in human and murine models.
Reports have suggested that T-bet and Eomes have cooperative or partially redundant functions (58), given that they both share a homologous DNA binding sequence (41). However, their specific contributions and mechanisms in regulating NK cell function, exhaustion and/or activation await further studies and elucidation. Interestingly, recent work confirms that while T-bet and Eomes do indeed compete for the same T-box consensus sequence, increasing the concentration of one transcription factor can displace and reduce binding of the other to the same consensus sequence (53). Additionally, binding of T-bet or Eomes results in differential transcriptional control. For example, in $\mathrm{T}$ cells, $\mathrm{T}$ bet is a strong repressor of PD-1 (59), however, Eomes binding to the same T-box sequence upstream of the PD-1 gene results in a much weaker repressive activity (53). Whether or not such a mechanism is relevant to NK cells and whether it could be a contributor to NK dysfunction is still unknown.

In recent years, it has been reported that NK cells can be converted to ILC1-like cells, which display poorer cytotoxic capabilities (60), as evident from reduced control over tumour burden and metastasis $(61,62)$. Distinct from NK cells, the ILC1s do not express Eomes (60), further implicating this T-box transcription factor in marking functional and mature NK cells rather than its less cytotoxic ILC1 counterpart. It is also possible that previous studies showing the downregulation of Eomes $(31,55)$ and the corresponding reduction in NK cell function could have been the result of NK cells acquiring an ILC1-like phenotype, although this remains to be further proven. Early studies initially used CD49a and CD 49b to distinguish between both cell types, with NK cells characterised as $\mathrm{CD} 49 \mathrm{a}^{-} \mathrm{CD} 49 \mathrm{~b}^{+}$and ILC1s as $\mathrm{CD} 49 \mathrm{a}^{+} \mathrm{CD} 49 \mathrm{~b}^{-}$ (60). However other groups have also reported the expression of CD49a ${ }^{+}$NK cells in the liver as well as in lung and blood $(63,64)$, thus complicating the use of these two markers in distinguishing between NK cells and ILC1s. Much subsequent data also suggested the difficulty and lack of any distinct marker in delineating ILC1s from NK cells, due to overlapping phenotypes in different tissues and contaminating cell types based on gating strategies (65). Despite the difficulty in differentiating between NK cells and ILC1s through the use of CD49a/b, it is perhaps still worth noting that peripheral NK cells from prostate cancer patients also express CD49a, along with high levels of the inhibitory receptors PD-1 and TIM-3, and exhibit impaired degranulation (66). Tumour-infiltrating NK cells with poor cytotoxicity and upregulated inhibitory receptors were also found to express CD49a in hepatocellular carcinoma patients $(67,68)$. Hence, regardless of whether or not the observed cell subsets are indeed NK or actually ILC1, these studies suggest that CD49a could possibly be used as a marker of dysfunctional NK cells. Therefore, it might be necessary and useful to study other possible markers of ILC1s, for example CD127 and CD69, although these markers should still be used with caution as they appear to be differentially expressed in ILC1s in various tissues $(69,70)$. Further exploration of this controversy and insights into the plasticity of the NK cells and ILC1s could provide new perspectives on how the pro-tumorigenic factors and physicochemical conditions in the tumour microenvironment (TME) might shape the NK cell response. 
In summary, we propose that the characterisation of dysfunctional NK cells goes beyond functional impairment and an altered surface receptor phenotype. An all-encompassing definition for NK cell exhaustion may thus include the expression of surface markers such as CD $49 \mathrm{a} / \mathrm{b}$ as well as expression of key T-box transcription factors (Figure 1), although this should be studied in greater detail in the context of NK cells and in cancer.

\section{CONTEXT-SPECIFIC MECHANISMS DRIVING ALTERED NK CELL PHENOTYPES IN THE TUMOUR MICROENVIRONMENT}

The altered surface receptor expression and transcriptional programs observed in cancer-associated NK cells are known to perturb the downstream signalling programs mediated by these receptors, such as the proinflammatory DNA-PKCs-Akt-NF- $\kappa \mathrm{B}$, MAPK, AKT and ERK signalling pathways (19). The proper regulation of these signalling cascades in healthy NK cells drives appropriate NK cell gene expression, target cell conjugation, degranulation, cytokine release and cytotoxicity (19). The loss of NK cell function has been shown to occur progressively, correlating with disease severity in cancers $(71,72)$. Since the functions of NK cells are regulated by signals from activating and inhibitory receptors, with many of these receptors converging onto the same pathways regulating NK cell cytotoxicity [as mentioned (19)], it is thus likely that any alteration in signalling will drive progressive impairment of NK cell function. The restoration of NK cell function and cytotoxicity upon targeting these receptors through blockade or overexpression (Table 1) have also firmly established that these phenotypic differences play a crucial role in mediating $\mathrm{NK}$ effector functions. Despite such attempts at reviving NK functions, the lack of a singular consistent exhausted phenotype reported by various groups suggests that

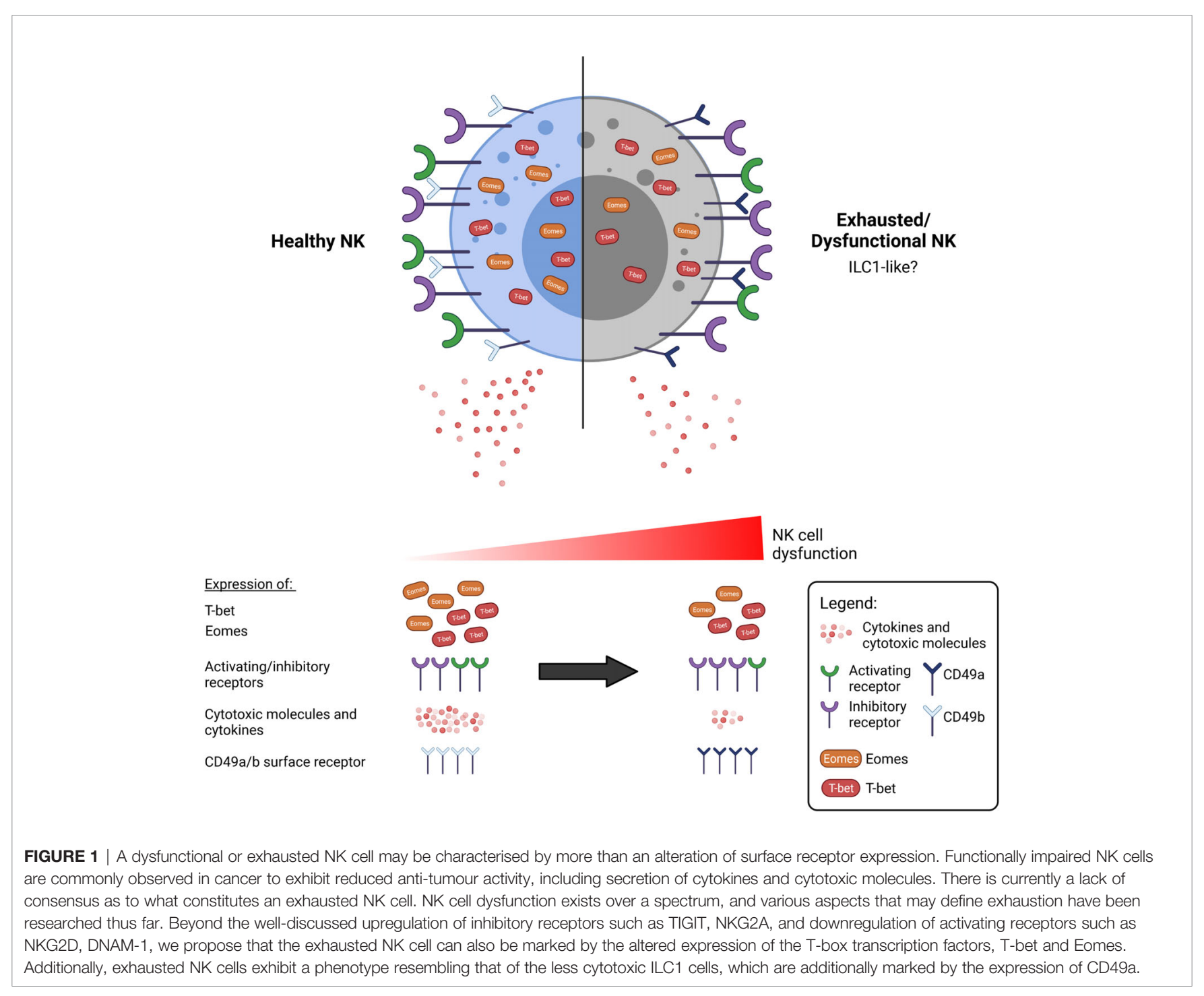


dysregulation of NK cell function is likely modulated in a tumour- and context-specific manner. The heterogeneity in the TME in different cancer types, as well as between individuals harbouring the same cancer would demand an array of NK phenotypes to cater to varying contexts. Thus, while strategies to restore NK to a healthy phenotype are poised as promising new avenues to be further explored for cancer immunotherapy, it is imperative to understand the specific mechanisms in the TME contributing to such phenotypic and functional alterations.

\subsection{Loss of Tumour Cell Immunogenicity Prevents NK Cells From Recognizing Cancer Cells}

Tumour progression is associated with the presence of a TME that is tolerant and immunosuppressive, which results in the evasion of cancer cells from immune surveillance. The heterogeneity of tumour cells in the TME such as differential ligand profile and secreted factors (73), further contributes to the downregulation of NK cell function against cancer. NK cell engagement with target cells and ligand-receptor interaction are thought to be the first steps leading to the formation of the immune synapse (contact point between cancer cell and NK cell) and subsequent activation of NK cytolytic capability (74). Therefore, it is deemed that the mechanisms of immune escape by cancer cells would occur largely through the modification of cancer cell ligands or NK surface receptors, or both.

The downregulation of activating ligands and upregulation of inhibitory ligands in immune responsive cells are associated with tumour progression, which is accompanied by a loss of tumour immunogenicity. Thus, the increased engagement with inhibitory ligands, or lack of engagement with activating ligands on cancer cells shifts the NK cell towards an inhibited state, resulting in failed tumour clearance. Some mechanisms underlying the alteration of ligand expression in tumour cells include the dysregulation of microRNA (miRNA), which has been observed in many cancers (75). miRNA dysregulation decreases the expression of activating ligands, MICA/B $(76,77)$ and ULBP2 $(76)$, and increases the expression of inhibitory ligands, PD-L1 (78) and MHC class I molecules $(79,80)$ on tumour cells, which can limit the immunosurveillance capabilities of NK cells. Furthermore, posttranslational modifications such as ubiquitination and SUMOylation of ligands expressed in cancer cells can alter the localization and activities of the ligands (81). For example, downregulation of PVR, the activating ligand for the receptor DNAM-1, is attributable to its SUMOylation in multiple myeloma, resulting in its intracellular localisation (82). In Kaposi's sarcoma-associated herpesvirus infection, MICA, which is a ligand for NKG2D activating receptor, undergoes ubiquitination, which prevents its cell surface localization (83). The observation of similar intracellular compartmentalisation and regulation occurring with the NK cell ligand MICA in Kaposi's sarcoma (83) shows that such a mechanism of regulation may be generalizable across different disease contexts. These observations (e.g., ubiquitination of NK receptor ligands) also increase the possibility that the expression and compartmentalisation of other ligands for NK cell receptors may be similarly regulated through different mechanisms of post-translational modifications.
The above-mentioned mechanisms are non-exhaustive and, on the whole, traditionally enable tumour escape from NK immunosurveillance through shifting the balance of ligand expression towards generating a decreased activating signal in NK cells. However, high expression of activating ligands has been observed in some tumours, although this causes the unexpected downregulation of the corresponding NK cell receptors, leading to NK cell dysfunction instead of augmenting tumour surveillance. For example, the high and sustained expression of NKG2D ligands on many tumours results in downregulation of NK cell NKG2D receptor through endocytosis $(84,85)$, which is believed to be a feedback mechanism regulating NK cell tolerance (86). Current anti-cancer chemotherapy regimens may also cause the upregulation of NKG2D ligands $(87,88)$, and while this may transiently upregulate NK cytotoxicity, a sustained and prolonged period of high ligand expression for cancer immunotherapy could exhaust NK cytotoxicity and pose an area of concern for long-term efficacy of NK cell function. The recognition of tumour cells and subsequent regulation of NK cell activity is thus not simply based on a straightforward interaction of a receptor with its cognate ligand leading to receptor activation. Thus, the robustness of NK cell phenotype in response to cancer cells are important considerations in the design of future therapeutic strategies targeting NK cell receptors.

\subsection{Downregulation of Intrinsic NK Cell Function by Factors in the TME}

Apart from a lack of tumour immunogenicity, soluble factors in the TME may also alter intrinsic NK cell function, thus further contributing to poor NK cell antitumour activity. For example, this can occur through the regulation of NK cell surface receptors, NK cell gene expression and metabolism, and will be discussed in this section.

The well-studied immunosuppressive cytokine, TGF- $\beta$, is key for cancer progression and it is known to elicit responses from stromal cells in the TME (89). Various cancer types secrete high levels of TGF- $\beta$ with wide-ranging effects on NK cells in the TME. Recent studies indicate that a high level of TGF- $\beta$ in the TME further promotes expression of TGF- $\beta$ receptors on NK cells resulting in a positive feedback loop (90). Prolonged exposure to TGF- $\beta$ significantly downregulates expression of NK cell activating receptors NKG2D, CD16, and NKp30, while upregulating the death ligand FasL and inhibitory receptor NKG2A in healthy donor NK cells (91), which dulls the recognition of target cells. This regulation of NK cell receptors by TGF- $\beta$ has been shown to occur via various miRNA pathways (92). Additionally, TGF- $\beta$ reduces T-bet expression through SMAD3 signalling, resulting in decreased expression of its target gene $\operatorname{IFN} \gamma(93)$, which would contribute to a reduction in NK cell function. Indeed, upon continuous stimulation with TGF- $\beta$, NK cells from healthy donors demonstrated reduced cytotoxicity against osteosarcoma cell lines, despite increased degranulation (91). Such chronic exposure to TGF- $\beta$ is likely to be an accurate representation of TGF- $\beta$ secretion by cancer cells in the TME.

The mammalian target of rapamycin (mTOR) forms two complexes known as mTORC1 and mTORC2. While mTORC1 
integrates signal from growth factors and metabolism, mTORC2 is mainly involved in growth and proliferation (94). In NK cells, it was demonstrated that priming by dsRNA mimetic poly (I:C) or IL15 activates mTORC1 and 2, which results in enhanced metabolism (95). The enhanced metabolism in NK cells characterised by enhanced glycolysis correlates positively with the production of cytolytic molecules such as granzyme B (96). Interestingly, TGF- $\beta$ in the tumour microenvironment is able to cross-talk with mTOR signalling pathway. Recently, TGF- $\beta$ has been shown to induce early inhibition of mTOR activity in NK cells by opposing the phosphorylation of mTOR substrates S6, $4 \mathrm{EBP} 1$ and AKT. Furthermore, the inhibitory effects of TGF- $\beta$ were comparable to the mTOR inhibitor rapamycin, thereby limiting metabolic activities in activated NK cells (97). This was one of the few studies that directly investigated the molecular mechanism of TGF- $\beta$ inhibition on NK cells. However, there are still discrepancies on whether TGF- $\beta$ signalling and mTOR inhibition (e.g. by rapamycin) converges. For instance, TGF- $\beta$ induces TRAIL expression while mTOR inhibition does otherwise (97). Furthermore, it was previously demonstrated in other cell types that TGF- $\beta / \mathrm{Smad} 3$ signalling activates mTOR to promote collagen production by increasing HIF- $1 \alpha$ expression (98). Hence, it is possible that there exists an unknown scaffold protein that spatio-temporally regulates TGF- $\beta$ inhibition of mTOR in NK cells.
Other than TGF- $\beta$, tumour cells also secrete many other immunosuppressive factors, for example, PGE2, PCLP1, IDO, which have been found to inhibit NK cell function and downregulate activating receptor expression (99, 100). However, unlike TGF- $\beta$, the mechanisms through which these cytokines function to regulate NK cells, and whether and how they drive other phenotypic changes beyond altered receptor expression, are unclear and still await further studies. A more detailed review on these soluble factors in the TME, and their suppressive effects on NK immunosurveillance capabilities has been provided by Melaiu et al. (101).

\subsection{Inhibition of NK Cell Cytotoxicity by Other Immune Cells in the TME}

The TME harbours a diverse repertoire of immune cells from innate and adaptive immune systems. Various soluble factors produced by these cells and cross-talks between them are a major contributor towards the suppressive conditions that allow for tumour progression and the impairment of $\mathrm{NK}$ cell function (Figure 2).

Macrophages are typically categorised into the classical M1 or the alternatively activated M2 macrophages, and this differential polarisation occurs as a result of different activation stimuli (102). M1 macrophages secrete pro-inflammatory cytokines and kill pathogens, whereas M2 macrophages are anti-

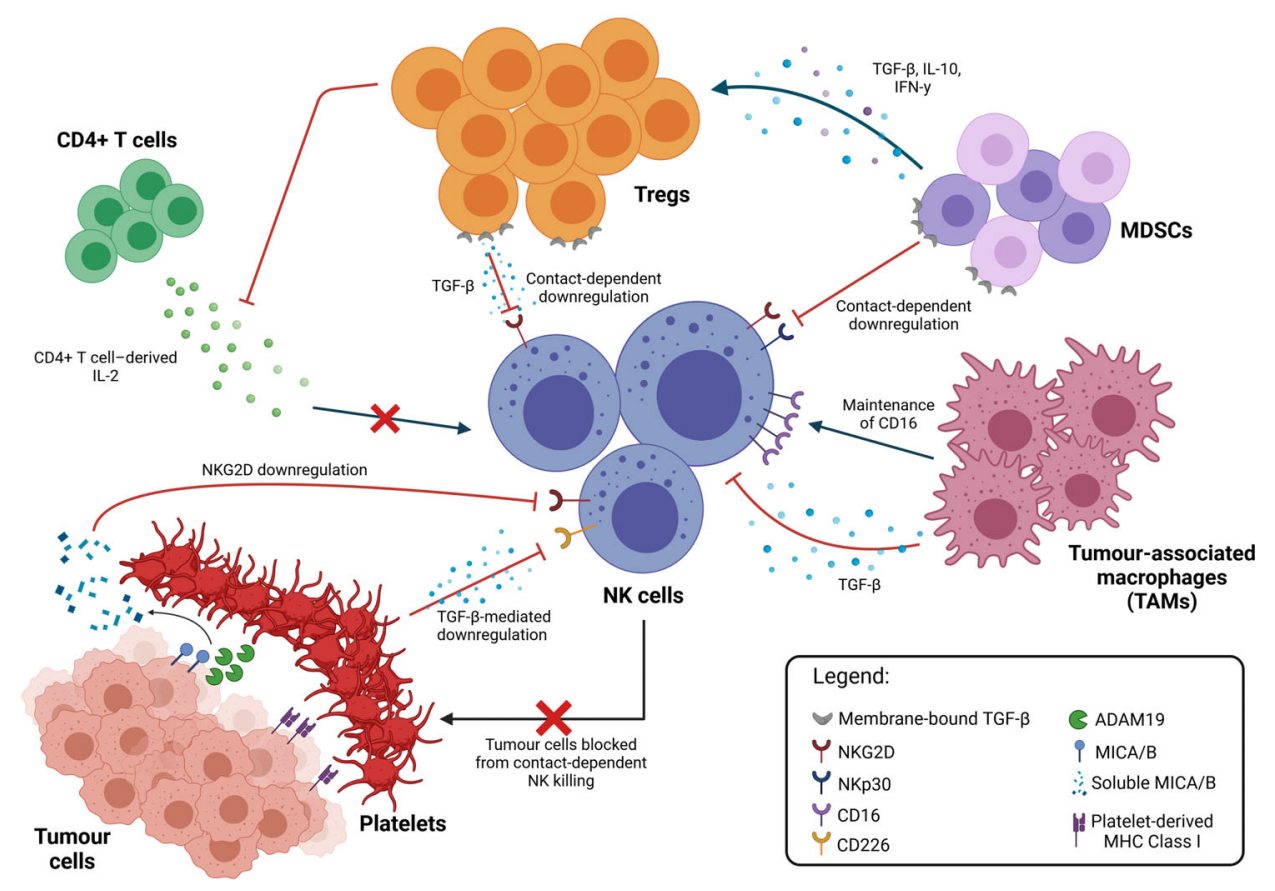

FIGURE 2 | Inhibition of NK cell cytotoxicity by other immune cells. Immune suppressive cell types in the TME interact directly with NK cells to inhibit their function through both contact-dependent and contact-independent downregulation of NK cell activating receptors, typically mediated by TGF- $\beta$. TAMs promote the maintenance of membrane-bound CD16, which reduces NK activation. NK cell function can also be modulated indirectly through multiple interactions between these different cell types. Cytokine secretion by MDSCs promote the expansion of Tregs, which apart from directly inhibiting NK cell functions, also limits the availability of IL-2 from CD4+ T cells, thus preventing NK cell stimulation. Platelets in the TME also interact with tumour cells directly, shielding them from NK cell recognition and killing; cleaving activating ligands on the tumour cell surface; and equipping tumour cells with MHC Class I molecules to facilitate immune evasion. 
inflammatory and tumour-promoting (103). Tumour-associated macrophages (TAMs) make up the majority of immune cells found in the tumour site (104). Unsurprisingly, TAMs express an M2-like phenotype in solid cancers, and large numbers of M2 TAMs correlate with poorer prognosis (105). M2 TAMs inhibit NK cell function $v i a$ the secretion of immunosuppressive TGF- $\beta$ (refer to section 4.2 for details) and in a contact-dependent manner, to reduce the production of IFN $\gamma$ and TNF $\alpha(106,107)$. Additionally, it has also been proposed that under specific chronic inflammatory conditions of cancer, TAMs protect tumour cells from NK cytotoxicity by preventing the shedding of membrane-bound CD16 (108). CD16 is an Fc receptor whose shedding indicates NK cell activation and increases NK engagement with target cells (109). While the maintenance of surface CD16 indicates inhibition of NK cell function, it is worth noting that simultaneously, CD16 acts as an important activating receptor in antibody-dependent cytotoxicity, and it is a wellexplored therapeutic target (110). Engagement of CD16 with therapeutic antibodies has been shown to improve NK cell response to restimulation and result in higher cytotoxicity towards tumour cells (111). Thus, despite being a seemingly tumour-protective mechanism, the maintenance of CD16 on NK cells by TAMs may instead present a window of opportunity when viewed from a therapeutic intervention perspective.

Myeloid-derived suppressor cells (MDSCs) consist of progenitors and precursors of myeloid cells (112), which are found in significantly higher numbers throughout tumour progression (113). MDSCs express membrane-bound TGF- $\beta$, which has been found to impair NK cell functions (113). In vitro, coculture with NK cells revealed a downregulation of NK cell cytotoxicity through STAT5-mediated activity (114). Interaction between MDSC and NK cells also downregulates NK cell receptor, NKp30, and blockade of NKp30 relieves the MDSCinduced inhibitory effects on NK cells (115). These observations suggest that MDSCs express ligands that inhibit NK cell functions through a cell-cell contact-dependent manner. Although generally accepted to be immunosuppressive, it appears that whether MDSCs function to activate or inhibit NK function, is context-dependent. Indeed, another study identified RAE-1 expression on MDSCs to induce NK activation in part through the NKG2D receptor (116). Furthermore, a plethora of cell types and soluble factors in vivo also contributes to the complexity of $\mathrm{NK}$ activation.

Regulatory T cells (Tregs) are the immunosuppressive subset of $\mathrm{CD}^{+} \mathrm{T}$ cells, and their upregulation is typically correlated with poor prognosis and cancer progression (117). In healthy individuals, crosstalk between Tregs and NK cells is an important self-tolerance mechanism (118). However, in cancer patients, elevated Treg levels are often found to correlate with low frequency and poor function of NK cells (119), suggesting a disrupted Treg-NK cell-cell balance or interaction. Tregs have been found to limit the availability of $\mathrm{CD} 4^{+} \mathrm{T}$ cell-derived IL-2, which is required to stimulate NK cells (120). Similar to MDSCs, membrane-bound TGF- $\beta$ on Tregs was also suggested to suppress NK cell cytotoxicity and downregulate the expression of activating receptor, NKG2D $(121,122)$. However, the inhibitory effects of Treg membrane-bound TGF- $\beta$ on NK cells appear to be distinct from the effects of MDSC membrane-bound TGF- $\beta$ (113), as discussed above (section 4.2). This suggests important distinctions between the mechanisms contributing to NK cell exhaustion by different immune cell types in the TME.

Platelets have also been increasingly recognised as another key player contributing to cancer progression and metastasis (123). The inhibition of NK cell function by platelets was first discovered to be through providing a physical barrier to tumour cells, directly protecting them from contact-dependent NK killing (124). Beyond a physical barrier, platelet cloaking also modulates the expression of $\mathrm{NK}$ cell receptors and corresponding tumour cell ligands (125). For example, they promote the loss of the NKG2D ligands like MICA/B on tumour cells, possibly through upregulating the expression of ADAM19, a protease responsible for MICA/B cleavage (126). The release of MICA/B into the TME further inhibits NK cell activity, since soluble NKG2D ligands are known to suppress NKG2D receptor expression on NK cells (127). Downregulation of other NK cell activating receptor ligands, CD112 and CD155, was also observed in platelet-cloaked breast cancer cells, along with their corresponding activating receptor, CD226 on NK cells (126). This was further shown to be attributable to the presence of platelet-derived TGF- $\beta$ (126). Interaction and contact between platelets and tumour cells also promotes the transfer of platelet MHC class I molecules to tumour cells via trogocytosis (128). This facilitates tumour evasion of immune response as tumour cells are no longer recognised via the 'missing self mechanism. Additionally, like all other cell types in the TME, platelets release a large variety of chemokines and soluble factors, which can serve to recruit other adaptive and innate immune cells to the tumour site (129), many of which interplay with NK cells with potentials for immunomodulating NK cytolytic functions.

\subsection{Altered Cytoskeletal Dynamics in Both NK and Cancer Cells - A 'Tug-of-War'}

As essential players in initiating and regulating NK cell function, NK cell surface receptors and their corresponding ligands have understandably been the subject of intense scrutiny and research. Here, we highlight the often-overlooked roles of the cell cytoskeletal network in the regulation of NK cell effector function, which arguably, is largely accountable for NK cell dysfunction in the TME.

The cell cytoskeletal network consists of long filamentous components represented by the microtubule and actin. Apart from modulating and organising the internal architecture of the cell, these cytoskeletal components along with their accessory proteins are instrumental in the generation of intracellular forces for mechanotransduction and signalling. The coordinated efforts of NK cytoskeleton in response to transformed cancer cells serves at least three functions: (i) the formation and organization of immune synapse for lytic granule secretion, (ii) the establishment of cell polarity through microtubule-organizing centre (MTOC) and (iii) the modulation of NK receptor nanoscale organization and interaction with tumour ligands. These processes amplify into a multitude of indispensable 
arsenal for NK cells to fight cancer cells and will be reviewed in more detail in the following sections.

\subsubsection{Microtubules - Beyond a Roadmap for Granule Trafficking}

The microtubules are helical lattices that are assembled from repeating units of polymerized $\alpha$ and $\beta$ tubulin monomers. They originate from the MTOC, which consists of the centrosomes and pericentriolar material. In eukaryotic cells, microtubules function as an architectural framework that augments structural organization of internal organelles (e.g., the nucleus and cytoskeletal components). In addition, they are the internal transport network which motor proteins such as kinesin and dynein traffic along. In the context of NK cells, much has been focused on how MTOC organization and orientation regulates NK cytotoxicity.

The reorientation of MTOC to the immune synapse is a rapid event that may occur as quickly as 5 minutes after receptor engagement/stimulation (130). Unfortunately, there is a lack of mechanistic understanding of MTOC orientation in NK cell response to cancer cells. Limited data suggests that activating receptors (e.g. NKG2D, NKp46 and NKp30) on NK cells activate two non-redundant signalling pathways, the PI3K $\rightarrow$ ERK2 and the PLC $\gamma \rightarrow$ JNK1 pathways for MTOC polarization (131). The integrin, LFA-1 on NK cells was also identified to facilitate the adhesion of NK to target cells and mediate polarization of lytic granules containing perforin through the engagement of ICAM1 ligand expressed in target cells (132). However, NK cells in the TME often lack or downregulate one or more activating receptors, and whether there exists receptor redundancy for MTOC polarization, remains poorly defined. Interestingly, the overexpression of ICAM-1 is observed in several cancer cells e.g. breast and lung cancers $(133,134)$. Hence, it has been construed that LFA-1 expression on NK cells is the main driver of MTOC polarization during $\mathrm{NK}$-antitumor immunosurveillance. Subsequently, it was found that the accumulation of PKCe, $\mathrm{PKC} \eta$, and $\mathrm{PKC} \theta$ in $\mathrm{NK}$ cells precedes MTOC reorientation since siRNA knockdown of these proteins disrupted MTOC reorientation (135). Simultaneously, lytic granules move towards the MTOC with the help of the motor protein dynein to facilitate the convergence of lytic granules to the immune synapse (136). The exact motor protein that lytic molecules traffic along the microtubule is under debate. In the context of NK-cancer immunomodulation, much less is known on whether and how NK-resistant cancer cells can affect microtubule function, viz whether cancer cells affect lytic granule trafficking, convergence and/or MTOC polarization. A recent study provided evidence of defective granule polarization (but not granule clustering) in NK92 cells upon encountering NK-resistant breast cancer cells (137). These findings in part suggest and support previous reports that, (i) granule convergence/clustering precedes MTOC polarization towards the immune synapse in the context of NK-cancer immunosurveillance and (ii) cancer cells immunomodulate NK signalling by the perturbation of MTOC orientation signals (e.g. PLC $\gamma \rightarrow$ JNK1 pathways). Indeed, the PLC $\gamma$ pathway that promotes MTOC polarization was shown to be triggered by NK activating receptors (131), which are often downregulated in the tumour microenvironment.

\subsubsection{Actin Dynamics for NK Cytotoxicity}

The actin network provides the structural basis for immune synapse formation and function. Along with actin associated proteins (e.g. ARP2/3, WASp, Wave1 Cdc42 etc.), the actin complexes are the major drivers of NK cell effector function against foreign entities (138). Hence, it is unsurprising that proper regulation of actin polymerization, dynamics and organization is key for the formation of the immune synapse and subsequent release of cytotoxic molecules, as well as for promoting NK cell motility and effective migration and infiltration into tumour sites (136).

De novo actin accumulation and rearrangement at the immune synapse marks the start of the effector stage of NK degranulation and this is a critical step towards eliciting an effective cytotoxic response. Indeed, actin targeting drugs such as cytochalasin (139), lantrunculin (140) or jasplakinolide (141) limit NK cytotoxicity. A study utilizing live-cell super-resolution microscopy overcame the spatio-temporal resolution limitations of NK cells (142) and demonstrated that the stochastic clearance, formation and disappearance of filamentous actin (F-actin) at the immune synapse is critical for size permissive degranulation of cytolytic components (142). In addition, various actin associated proteins were shown to be important for NK lytic function. For instance, the hematopoietic cell-specific action associated protein coronin $1 \mathrm{~A}$ colocalizes with F-actin at the immune synapse and regulates F-actin density for size permissive granule penetrance to the membrane (143). The non-muscle myosin IIa generates contractility and is also important for degranulation (144). Dysregulation of contractility did not affect lytic granule conjugation but increased actin density at the plasma membrane and severely limited degranulation (142). There are more than 100 actin associated proteins that regulate NK cytotoxicity against cancer cells, which are beyond the scope of this review. A detailed review on these actin associated proteins and how they affect NK immune synapse formation and function can be found in a recent review by Ben-Shmuel et al. (136).

\subsubsection{Spatio-Temporal Cytoskeletal Co-Ordination of NK Cytolysis}

There is limited information based on NK-cancer co-culture models or in vivo research on how cancer cells can directly affect NK immune synapse and actin dynamics. A recent study suggested that activating signals at the immune synapse promote fast actin retrograde flow and reduces $\beta$-actin, SHP-1 interaction, thereby enhancing NK cytotoxicity (138). In addition, actin polymerisation has been established to be a downstream event of NK activating receptor signalling (145), which is often dysregulated in cancers. Wilton et.al., showed that the actin regulatory protein Ena/VASPlike (EVL) is recruited to the immune synapse by NKG2D-DAP10 complex and involves the DAP10-dependent Grb2-VAV1 associated pathway (145). Looking forward, there are evidences suggesting that actin-mediated intracellular contractility could alter nuclear mechanotransduction (146), which results in chromatin remodelling and impacts the intracellular localisation of 
transcription factor co-activators (147). If applied to the T-box transcription factors, the actomyosin based contractility could be conversely altered with implications on the expression and localisation patterns of T-bet and Eomes, which are key in regulating NK cell functions and their antitumour activities, as discussed above (Section 3). In addition, since the TME is known to be hypertonic (148), there is an underappreciated link to how the TME regulates NK cell function through altering its contractility, independent of NK surface receptors.

In cancer cells, actin remodelling has also been found to aid evasion from NK killing. For example, accumulation of actin at the immune synapse in breast cancer cells encountering NK limited the accumulation of the cytotoxic molecule granzyme $\mathrm{B}$ in the cancer cells, protecting them from lysis and resulting in lowered apoptosis of the tumour cell (149). The cancer cell lines used in this study (149) exhibited different levels of actin accumulation at the immune synapse, and it was suggested that compared to epithelial-like cancer cells, mesenchymal-like cancer cells had a higher capacity to generate actin accumulation at the immune synapse, thus contributing to differential and greater resistance to NK killing. The cellular cytoskeletal dynamics on both sides of the immune synapse, which influences the contact-dependent nature of NK-mediated killing, appears to play a pivotal role in the success or failure of NK cell elimination of target cells. This can occur as a result of factors inherent to the cancer type itself, but may also be attributable to the hypertonicity of the TME (148) which can induce cellular contractility.

Thus far, many studies have focused on the functional consequences of cytoskeleton dynamics in regulating NK cell function. It is therefore pertinent for future studies to unravel the molecular and biophysical mechanisms that regulate a dynamic cytoskeletal network for NK cytotoxicity against cancer cells. For instance, to ask whether scaffold proteins exist to spatiotemporally coordinate lytic granule trafficking, MTOC polarization and actin dynamics at the immune synapse. Such information will be helpful for understanding whether and how NK exhaustion can be phenotypically characterised by altered cytoskeletal components. Furthermore, ex vivo perturbation of the cytoskeletal network in NK cells may hold promising future therapeutic opportunities.

\section{LOOKING BEYOND TARGETING NK CELL RECEPTORS FOR THERAPEUTIC ADVANCES}

Many studies have thus far focused on elucidating the effects of individual TME players on NK cell function, which has provided valuable insights into the various mechanisms underlying NK cell exhaustion. As reviewed herein, these mechanisms tend to converge on the alteration of NK cell surface receptors, hence much emphasis is currently placed on targeting of these surface receptors in an effort to restore NK cell function. However, given the large number of NK cell receptors, the complexity of the TME and the numerous players exerting their inhibitory effects on NK cells via multiple receptors, it is challenging for current therapies targeting specific receptors to contend with the inhibitory effects of the TME in vivo. Therefore, along with current developments in targeting NK cell receptors, alternative approaches for the revitalisation of NK cells should also be taken into consideration. For instance, the T-box transcription factors in NK cells have been shown to be key for NK cell function and development, and several reports thus far have suggested their expression levels to be dysregulated in exhausted NK cells. Given that significant progress has been made in developing drugs to target transcription factors (150), further study on how these transcription factors are precisely regulated by the TME may open up a new avenue of treatment to restore NK cells to their full cytotoxic capacity. To this end, whether and how transcriptional signals can be desensitized for 'self-tolerance' in response to persistent stimulation by cancer cells, could be addressed. Additionally, an increasing interest and understanding on how cytoskeletal dynamics shape NK cell cytotoxicity is anticipated to shed new insight into the regulation of NK cell function through its impact on transcription factor expression, receptor expression, and/or other yet to be elucidated mechanisms. The integration of these areas of knowledge will be key to the advancement of novel therapies that will holistically target multiple aspects of the exhausted NK cell.

The use of CAR-NK cells in immunotherapy has yielded optimistic results, and provides several advantages over CAR-T cells, such as improved tolerance, reduced toxicity as well as multiple sources from which NK cells can be derived (151). However, CAR-NK cells are still associated with various technical and biological limitations, such as difficulties in CAR delivery into NK cells, the short lifespan of NK cells in the absence of additional cytokine treatment, the requirement for ex vivo expansion prior to infusion, low tumour infiltration capacity and reduced cytotoxicity in vivo $(151,152)$. While strategies to engineer NK cells for improved performance are being studied, other areas of therapy are now also being explored for potential use in combination with established cancer therapy. One such area of interest is the use of nanomaterials such as liposomes and nano-emulsions to enhance NK cell activation as well as to modify the immunosuppressive TME (153). Additionally, other studies are also looking beyond the traditional checkpoint inhibition targets of NK surface receptors, towards proteins such CEACAM, chemokine receptors and even growth factors found in the TME; drugs targeting these molecules are already in early stage clinical trials (154). When used in tandem with existing NK cell-based therapy and other immune cell-based therapy or chemotherapy, there is greater hope that these emerging treatment options will provide increased synergy and efficacy, moving us towards achieving greater success in exploiting NK cells for cancer treatment.

Furthermore, recent advances in single cell studies involving genotyping and phenotyping have identified various NK cell phenotypes in the body $(155,156)$. These studies highlight the functional plasticity of NK cells, which results in a blurred boundary between 'young', 'mature' and 'exhausted' NK cells. For example, NK cells in the lungs have a more mature phenotype compared to those in other tissues. In mice, lung NK cells express high levels of mature markers NKp46, CD49b, CD11b, and Ly49 receptors (157). Systemic therapeutic interventions disregard the diverse subset(s) of 


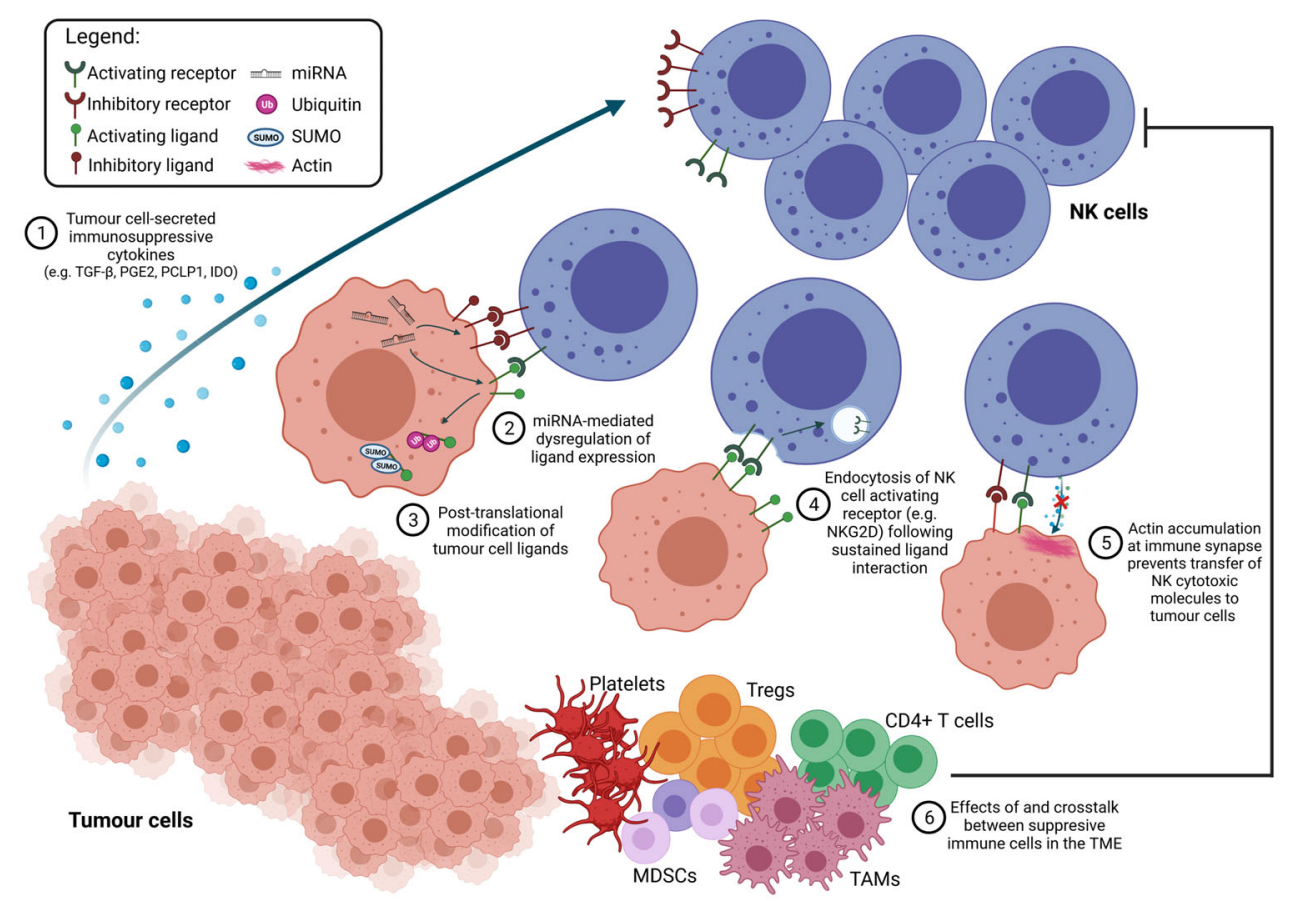

FIGURE 3 | TME factors suppress NK cell function. Tumour-intrinsic properties play a significant role in the downregulation of NK cytotoxicity through altering NK-cancer receptor-ligand interaction, which shifts the NK cell towards an inhibited/exhausted state. (1) The secretion of immunosuppressive cytokines modulates NK cell surface receptor expression. (2) Dysregulation of miRNA promotes the upregulation of inhibitory ligands and downregulation of activating ligands. (3) Upregulated post-translational modification processes (e.g., ubiquitination and SUMOylation) in tumour cells cause intracellular localisation of activating ligands, allowing tumour escape from NK cell recognition. (4) Chronic exposure to activating ligands on tumour cells promotes a feedback mechanism leading to endocytosis of NK cell activating receptors. (5) Altered cytoskeletal dynamics in tumours also contribute to tumour cell resistance to NK cell killing. Additionally, effective recognition of cancer by NK cells is hampered by (6) the multitude of other immune cells in the TME which not only downregulate NK function, but also aid tumour cells in evading NK cell recognition.

NK cells (e.g. periphery NK cells) and this could affect premature upregulation and/or downregulation of NK cell activities. Moreover, the jury is still out on whether and how NK cells can interchange their phenotype to adapt to a more effective killer phenotype in different tissues. Hence, future precision-guided medicine should be open to embrace omics to nail down a targeted approach for NKcancer immunomodulation.

This article has highlighted the uncertainty in characterising NK cell dysfunction, as well as recent studies made to widen our understanding of NK exhaustion. However, we also note the complex cell-cell interaction and molecular crosstalks occurring in the TME that contribute to, and shape NK cell function in distinct and complementary ways. With these large number of factors at play, it is clear that successful cancer immunotherapy should involve the use of combinatorial treatments, targeting

\section{REFERENCES}

1. Vivier E, Tomasello E, Baratin M, Walzer T, Ugolini S. Functions of Natural Killer Cells. Nat Immunol (2008) 9:503-10. doi: 10.1038/ni1582

2. Paul S, Lal G. Development and Function of Natural Killer Cells and Its Importance in Cancer Immunotherapy. In: . Immunology: Immunotoxicology, Immunopathology, and Immunotherapy Immunol (Elsevier), 117-40. doi: 10.1016/B978-0-12-809819-6.00009-5 different players in the TME, while also being mindful of the crosstalks between the various cell types present (Figure 3).

\section{AUTHOR CONTRIBUTIONS}

All authors contributed to the article and approved the submitted version.

\section{ACKNOWLEDGMENTS}

We thank the National Research Foundation, Singapore, for its funding to NUS for RIE-Related Roles for the SGUnited Jobs Initiative (NRF-MP-2020-0004).

3. Liu D, Jenkins RW, Sullivan RJ. Mechanisms of Resistance to Immune Checkpoint Blockade. Am J Clin Dermatol (2019) 20:41-54. doi: 10.1007/s40257-018-0389-y

4. Rosenberg J, Huang J. CD8+ T Cells and NK Cells: Parallel and Complementary Soldiers of Immunotherapy. Curr Opin Chem Eng (2018) 19:9-20. doi: 10.1016/j.coche.2017.11.006

5. Suen WCW, Lee WYW, Leung KT, Pan XH, Li G. Natural Killer Cell-Based Cancer Immunotherapy: A Review on 10 Years Completed Clinical Trials. Cancer Invest (2018) 36:431-57. doi: 10.1080/07357907.2018.1515315 
6. Bi J, Tian Z. NK Cell Dysfunction and Checkpoint Immunotherapy. Front Immunol (2019) 10:1999. doi: 10.3389/fimmu.2019.01999

7. Sun C, Sun HY, Xiao WH, Zhang C, Tian ZG. Natural Killer Cell Dysfunction in Hepatocellular Carcinoma and NK Cell-Based Immunotherapy. Acta Pharmacol Sin (2015) 36:1191-99. doi: 10.1038/aps.2015.41

8. Cózar B, Greppi M, Carpentier S, Narni-Mancinelli E, Chiossone L, Vivier E. Tumor-Infiltrating Natural Killer Cells. Cancer Discov (2021) 11:34-44. doi: 10.1158/2159-8290.CD-20-0655

9. Platonova S, Cherfils-Vicini J, Damotte D, Crozet L, Vieillard V, Validire P, et al. Profound Coordinated Alterations of Intratumoral NK Cell Phenotype and Function in Lung Carcinoma. Cancer Res (2011) 71:5412-422. doi: 10.1158/0008-5472.CAN-10-4179

10. Mamessier E, Sylvain A, Thibult ML, Houvenaeghel G, Jacquemier J, Castellano R, et al. Human Breast Cancer Cells Enhance Self Tolerance by Promoting Evasion From NK Cell Antitumor Immunity. J Clin Invest (2011) 121:3609-622. doi: 10.1172/JCI45816

11. Hodge G, Barnawi J, Jurisevic C, Moffat D, Holmes M, Reynolds PN, et al. Lung Cancer Is Associated With Decreased Expression of Perforin, Granzyme B and Interferon (IFN)- $\gamma$ by Infiltrating Lung Tissue T Cells, Natural Killer (NK) T-Like and NK Cells. Clin Exp Immunol (2014) 178:7985. doi: $10.1111 /$ cei.12392

12. Verma C, Kaewkangsadan V, Eremin JM, Cowley GP, Ilyas M, El-Sheemy MA, et al. Natural Killer (NK) Cell Profiles in Blood and Tumour in Women With Large and Locally Advanced Breast Cancer (LLABC) and Their Contribution to a Pathological Complete Response (PCR) in the Tumour Following Neoadjuvant Chemotherapy (NAC): Differential Rest. J Transl Med (2015) 13:180. doi: 10.1186/s12967-015-0535-8

13. Wherry EJ. T Cell Exhaustion. Nat Immunol (2011) 12:492-99. doi: 10.1038/ ni. 2035

14. McLane LM, Abdel-Hakeem MS, Wherry EJ. CD8 T Cell Exhaustion During Chronic Viral Infection and Cancer. Annu Rev Immunol (2019) 37:457-95. doi: 10.1146/annurev-immunol-041015-055318

15. Judge SJ, Murphy WJ, Canter RJ. Characterizing the Dysfunctional NK Cell: Assessing the Clinical Relevance of Exhaustion, Anergy, and Senescence. Front Cell Infect Microbiol (2020) 10:49. doi: 10.3389/fcimb.2020.00049

16. Merino AM, Kim H, Miller JS, Cichocki F. Unraveling Exhaustion in Adaptive and Conventional NK Cells. J Leukoc Biol (2020) 108:1361-68. doi: 10.1002/JLB.4MR0620-091R

17. Bi J, Tian Z. NK Cell Exhaustion. Front Immunol (2017) 8:760. doi: 10.3389/ fimmu.2017.00760

18. Cheent K, Khakoo SI. Natural Killer Cells: Integrating Diversity With Function. Immunology (2009) 126:449-57. doi: 10.1111/j.1365-2567.2009.03045.x

19. Chen Y, Lu D, Churov A, Fu R. Research Progress on NK Cell Receptors and Their Signaling Pathways. Mediators Inflamm (2020) 2020:1-14. doi: $10.1155 / 2020 / 6437057$

20. Wang F, Hou H, Wu S, Tang Q, Liu W, Huang M, et al. TIGIT Expression Levels on Human NK Cells Correlate With Functional Heterogeneity Among Healthy Individuals. Eur J Immunol (2015) 45:2886-97. doi: $10.1002 /$ eji.201545480

21. Sun C, Xu J, Huang Q, Huang M, Wen H, Zhang C, et al. High NKG2A Expression Contributes to NK Cell Exhaustion and Predicts a Poor Prognosis of Patients With Liver Cancer. Oncoimmunology (2017) 6: e1264562. doi: 10.1080/2162402X.2016.1264562

22. Van Hall T, André P, Horowitz A, Ruan DF, Borst L, Zerbib R, et al. Monalizumab: Inhibiting the Novel Immune Checkpoint NKG2A. J Immunother Cancer (2019) 7:263. doi: 10.1186/s40425-019-0761-3

23. Liu Y, Cheng Y, Xu Y, Wang Z, Du X, Li C, et al. Increased Expression of Programmed Cell Death Protein 1 on NK Cells Inhibits NK-Cell-Mediated Anti-Tumor Function and Indicates Poor Prognosis in Digestive Cancers. Oncogene (2017) 36:6143-53. doi: 10.1038/onc.2017.209

24. Benson DM, Bakan CE, Mishra A, Hofmeister CC, Efebera Y, Becknell B, et al. The PD-1/PD-L1 Axis Modulates the Natural Killer Cell Versus Multiple Myeloma Effect: A Therapeutic Target for CT-011, a Novel Monoclonal Anti-PD-1 Antibody. Blood (2010) 116:2286-94. doi: 10.1182/ blood-2010-02-271874

25. Guo Y, Feng X, Jiang Y, Shi X, Xing X, Liu X, et al. PD1 Blockade Enhances Cytotoxicity of In Vitro Expanded Natural Killer Cells Towards Myeloma Cells. Oncotarget (2016) 7:48360-74. doi: 10.18632/oncotarget.10235
26. Hsu J, Hodgins JJ, Marathe M, Nicolai CJ, Bourgeois-Daigneault MC, Trevino TN, et al. Contribution of NK Cells to Immunotherapy Mediated by PD-1/PDL1 Blockade. J Clin Invest (2018) 4654:68. doi: 10.1172/JCI99317

27. Judge SJ, Darrow MA, Thorpe SW, Gingrich AA, O’Donnell EF, Bellini AR, et al. Analysis of Tumor-Infiltrating NK and T Cells Highlights IL-15 Stimulation and TIGIT Blockade as a Combination Immunotherapy Strategy for Soft Tissue Sarcomas. J Immunother Cancer (2020) 8:e001355. doi: 10.1136/jitc-2020-001355

28. Zhang Q, Bi J, Zheng X, Chen Y, Wang H, Wu W, et al. Blockade of the Checkpoint Receptor TIGIT Prevents NK Cell Exhaustion and Elicits Potent Anti-Tumor Immunity. Nat Immunol (2018), 723-32. doi: 10.1038/s41590018-0132-0

29. Degos C, Heinemann M, Barrou J, Boucherit N, Lambaudie E, Savina A, et al. Endometrial Tumor Microenvironment Alters Human NK Cell Recruitment, and Resident NK Cell Phenotype and Function. Front Immunol (2019) 10:877. doi: 10.3389/fimmu.2019.00877

30. Chauvin JM, Ka M, Pagliano O, Menna C, Ding Q, DeBlasio R, et al. IL15 Stimulation With TIGIT Blockade Reverses CD155-Mediated NK-Cell Dysfunction in Melanoma. Clin Cancer Res (2020) 426:5520-33. doi: 10.1158/1078-0432.CCR-20-0575

31. da Silva IP, Gallois A, Jimenez-Baranda S, Khan S, Anderson AC, Kuchroo VK, et al. Reversal of NK-Cell Exhaustion in Advanced Melanoma by Tim-3 Blockade. Cancer Immunol Res (2014) 2:410-22. doi: 10.1158/2326-6066.CIR-13-0171

32. Attalla K, Farkas AM, Anastos H, Audenet F, Galsky MD, Bhardwaj N, et al. TIM-3 and TIGIT are Possible Immune Checkpoint Targets in Patients With Bladder Cancer. Urol Oncol Semin Orig Investig (2020) 1-4. doi: 10.1016/j.urolonc.2020.06.007

33. Dao TN, Utturkar S, Lanman NA, Matosevic S. Tim-3 Expression is Downregulated on Human Nk Cells in Response to Cancer Targets in Synergy With Activation. Cancers (Basel) (2020) 12:1-19. doi: 10.3390/ cancers 12092417

34. Carlsten M, Norell H, Bryceson YT, Poschke I, Schedvins K, Ljunggren H-G, et al. Primary Human Tumor Cells Expressing CD155 Impair Tumor Targeting by Down-Regulating DNAM-1 on NK Cells. J Immunol (2009) 183:4921-30. doi: 10.4049/jimmunol.0901226

35. Han B, Mao FY, Zhao YL, Lv YP, Teng YS, Duan M, et al. Altered NKp30, NKp46, NKG2D, and DNAM-1 Expression on Circulating NK Cells Is Associated With Tumor Progression in Human Gastric Cancer. J Immunol Res (2018) 2018:6248590. doi: 10.1155/2018/6248590

36. Sayitoglu EC, Georgoudaki AM, Chrobok M, Ozkazanc D, Josey BJ, Arif M, et al. Boosting Natural Killer Cell-Mediated Targeting of Sarcoma Through DNAM-1 and NKG2D. Front Immunol (2020) 11:40. doi: 10.3389/ fimmu.2020.00040

37. Konjević G, Mirjačić Martinović K, Vuletić A, Radenković S. Novel Aspects of In Vitro IL-2 or IFN- $\alpha$ Enhanced NK Cytotoxicity of Healthy Individuals Based on NKG2D and CD161 NK Cell Receptor Induction. BioMed Pharmacother (2010) 64:663-71. doi: 10.1016/j.biopha.2010.06.013

38. Kundu K, Ghosh S, Sarkar R, Edri A, Brusilovsky M, Gershoni-Yahalom O, et al. Inhibition of the NKp44-PCNA Immune Checkpoint Using a MAb to PCNA. Cancer Immunol Res (2019) 7:1120. doi: 10.1158/2326-6066.CIR19-0023

39. Glasner A, Isaacson B, Viukov S, Neuman T, Friedman N, Mandelboim M, et al. Increased NK Cell Immunity in a Transgenic Mouse Model of NKp46 Overexpression. Sci Rep (2017) 7:13090. doi: 10.1038/s41598-017-12998-w

40. Parodi M, Favoreel H, Candiano G, Gaggero S, Sivori S, Mingari MC, et al. NKp44-NKp44 Ligand Interactions in the Regulation of Natural Killer Cells and Other Innate Lymphoid Cells in Humans. Front Immunol (2019) 141:3819-33. doi: 10.3389/fimmu.2019.00719

41. Papaioannou VE. The T-Box Gene Family: Emerging Roles in Development, Stem Cells and Cancer. Dev (2014) 141:3819-33. doi: 10.1242/dev.104471

42. Townsend MJ, Weinmann AS, Matsuda JL, Salomon R, Farnham PJ, Biron CA, et al. T-Bet Regulates the Terminal Maturation and Homeostasis of NK and Vo14i NKT Cells. Immunity (2004) 20:477-94. doi: 10.1016/S10747613(04)00076-7

43. Daussy C, Faure F, Mayol K, Viel S, Gasteiger G, Charrier E, et al. T-Bet and Eomes Instruct the Development of Two Distinct Natural Killer Cell Lineages in the Liver and in the Bone Marrow. J Exp Med (2014) 20:47794. doi: $10.1084 /$ jem. 20131560 
44. Gordon SM, Chaix J, Rupp LJ, Wu J, Madera S, Sun JC, et al. Transcription Factors T-Bet and Eomes Control Key Checkpoints of Natural Killer Cell Maturation. Immunity (2012) 36:55-67. doi: 10.1016/j.immuni.2011.11.016

45. Pearce EL, Mullen AC, Martins GA, Krawczyk CM, Hutchins AS, Zediak VP, et al. Control of Effector CD8+ T Cell Function by the Transcription Factor Eomesodermin. Science (80-) (2003) 302:1041-43. doi: 10.1126/ science. 1090148

46. Sullivan BM, Juedes A, Szabo SJ, Von Herrath M, Glimcher LH. AntigenDriven Effector CD8 T Cell Function Regulated by T-Bet. Proc Natl Acad Sci USA (2003) 100:15818-23. doi: 10.1073/pnas.2636938100

47. Zhu Y, Ju S, Chen E, Dai S, Li C, Morel P, et al. T-Bet and Eomesodermin Are Required for T Cell-Mediated Antitumor Immune Responses. J Immunol (2010) 185:3174-83. doi: 10.4049/jimmunol.1000749

48. Buggert M, Tauriainen J, Yamamoto T, Frederiksen J, Ivarsson MA, Michaëlsson J, et al. T-Bet and Eomes Are Differentially Linked to the Exhausted Phenotype of CD8+ T Cells in HIV Infection. PloS Pathog (2014) 10:e1004251. doi: 10.1371/journal.ppat.1004251

49. Li J, He Y, Hao J, Ni L, Dong C. High Levels of Eomes Promote Exhaustion of Anti-Tumor CD8+ T Cells. Front Immunol (2018) 9:2981. doi: 10.3389/ fimmu.2018.02981

50. Paley MA, Kroy DC, Odorizzi PM, Johnnidis JB, Dolfi DV, Barnett BE, et al. Progenitor and Terminal Subsets of CD8+ T Cells Cooperate to Contain Chronic Viral Infection. Science (80-) (2012) 338:1220-25. doi: 10.1126/ science. 1229620

51. Jia B, Zhao C, Rakszawski KL, Claxton DF, Christopher Ehmann W, Rybka WB, et al. Eomes+T-Betlow CD8+ T Cells are Functionally Impaired and Are Associated With Poor Clinical Outcome in Patients With Acute Myeloid Leukemia. Cancer Res (2019) 79:1635-45. doi: 10.1158/0008-5472.CAN-18-3107

52. McLane LM, Ngiow SF, Chen Z, Attanasio J, Manne S, Ruthel G, et al. Role of Nuclear Localization in the Regulation and Function of T-Bet and Eomes in Exhausted CD8 T Cells. Cell Rep (2021). doi: 10.1016/j.celrep.2021.109120

53. Knox JJ, Cosma GL, Betts MR, McLane LM. Characterization of T-Bet and Eomes in Peripheral Human Immune Cells. Front Immunol (2014) 5:217. doi: 10.3389/fimmu.2014.00217

54. Gill S, Vasey AE, De Souza A, Baker J, Smith AT, Kohrt HE, et al. Rapid Development of Exhaustion and Down-Regulation of Eomesodermin Limit the Antitumor Activity of Adoptively Transferred Murine Natural Killer Cells. Blood (2012) 119:5758-68. doi: 10.1182/blood-2012-03-415364

55. Seo H, Jeon I, Kim BS, Park M, Bae EA, Song B, et al. IL-21-Mediated Reversal of NK Cell Exhaustion Facilitates Anti-Tumour Immunity in MHC Class I-Deficient Tumours. Nat Commun (2017) 8:15776. doi: 10.1038/ ncomms 15776

56. Verma R, Er JZ, Pu RW, Sheik Mohamed J, Soo RA, Muthiah HM, et al. Eomes Expression Defines Group 1 Innate Lymphoid Cells During Metastasis in Human and Mouse. Front Immunol (2020) 11:1190. doi: 10.3389/fimmu. 2020.01190

57. Intlekofer AM, Takemoto N, Wherry EJ, Longworth SA, Northrup JT, Palanivel VR, et al. Effector and Memory CD8+ T Cell Fate Coupled by T-Bet and Eomesodermin. Nat Immunol (2005) 6:1236-44. doi: 10.1038/ ni1268

58. Kao C, Oestreich KJ, Paley MA, Crawford A, Angelosanto JM, Ali MAA, et al. Transcription Factor T-Bet Represses Expression of the Inhibitory Receptor PD-1 and Sustains Virus-Specific CD8+ T Cell Responses During Chronic Infection. Nat Immunol (2011) 12:663-71. doi: 10.1038/ni.2046

59. Spits H, Bernink JH, Lanier L. NK Cells and Type 1 Innate Lymphoid Cells: Partners in Host Defense. Nat Immunol (2016) 17:758-64. doi: 10.1038/ni.3482

60. Gao Y, Souza-Fonseca-Guimaraes F, Bald T, Ng SS, Young A, Ngiow SF, et al. Tumor Immunoevasion by the Conversion of Effector NK Cells Into Type 1 Innate Lymphoid Cells. Nat Immunol (2017) 18:1004-15. doi: $10.1038 /$ ni.3800

61. Cortez VS, Ulland TK, Cervantes-Barragan L, Bando JK, Robinette ML, Wang Q, et al. SMAD4 Impedes the Conversion of NK Cells Into ILC1-Like Cells by Curtailing Non-Canonical TGF- $\beta$ Signaling. Nat Immunol (2017) 18:995-100. doi: 10.1038/ni.3809

62. Brownlie D, Scharenberg M, Mold JE, Hard J, Kekalainen E, Buggert M, et al. Expansions of Adaptive-Like NK Cells With a Tissue-Resident Phenotype in Human Lung and Blood. Proc Natl Acad Sci USA (2021) 118:e2016580118. doi: $10.1073 /$ pnas. 2016580118
63. Marquardt N, Béziat V, Nyström S, Hengst J, Ivarsson MA, Kekäläinen E, et al. Cutting Edge: Identification and Characterization of Human Intrahepatic CD49a + NK Cells. J Immunol (2015) 194:2467-71. doi: 10.4049/jimmunol.1402756

64. Riggan L, Freud AG, O'Sullivan TE. True Detective: Unraveling Group 1 Innate Lymphocyte Heterogeneity. Trends Immunol (2019) 40:909-21. doi: 10.1016/j.it.2019.08.005

65. Gallazzi M, Baci D, Mortara L, Bosi A, Buono G, Naselli A, et al. Prostate Cancer Peripheral Blood NK Cells Show Enhanced CD9, CD49a, CXCR4, CXCL8, MMP-9 Production and Secrete Monocyte-Recruiting and Polarizing Factors. Front Immunol (2021) 11:586126. doi: 10.3389/fimmu.2020.586126

66. Sun H, Liu L, Huang Q, Liu H, Huang M, Wang J, et al. Accumulation of Tumor-Infiltrating Cd49a Nk Cells Correlates With Poor Prognosis for Human Hepatocellular Carcinoma. Cancer Immunol Res (2019) 7:1535-46. doi: 10.1158/2326-6066.CIR-18-0757

67. Zecca A, Barili V, Rizzo D, Olivani A, Biasini E, Laccabue D, et al. Intratumor Regulatory Noncytotoxic NK Cells in Patients With Hepatocellular Carcinoma. Cells (2021) 10:614. doi: 10.3390/cells10030614

68. Meininger I, Carrasco A, Rao A, Soini T, Kokkinou E, Mjösberg J. TissueSpecific Features of Innate Lymphoid Cells. Trends Immunol (2020), 902-17. doi: 10.1016/j.it.2020.08.009

69. Jiao Y, Huntington ND, Belz GT, Seillet C. Type 1 Innate Lymphoid Cell Biology: Lessons Learnt From Natural Killer Cells. Front Immunol (2016) 7:426. doi: 10.3389/fimmu.2016.00426

70. Gallois A, Silva I, Osman I, Bhardwaj N. Reversal of Natural Killer Cell Exhaustion by TIM-3 Blockade. Oncoimmunology (2014) 3:1-3. doi: $10.4161 / 21624011.2014 .946365$

71. Jun E, Song AY, Choi JW, Lee HH, Kim MY, Ko DH, et al. Progressive Impairment of NK Cell Cytotoxic Degranulation is Associated With TGF- $\beta 1$ Deregulation and Disease Progression in Pancreatic Cancer. Front Immunol (2019) 10:1354. doi: 10.3389/fimmu.2019.01354

72. Shembrey C, Huntington ND, Hollande F. Impact of Tumor and Immunological Heterogeneity on the Anti-Cancer Immune Response. Cancers (Basel) (2019) 11:1217. doi: 10.3390/cancers11091217

73. Orange JS, Harris KE, Andzelm MM, Valter MM, Geha RS, Strominger JL. The Mature Activating Natural Killer Cell Immunologic Synapse is Formed in Distinct Stages. Proc Natl Acad Sci USA (2003) 100:14151-56. doi: 10.1073/ pnas. 1835830100

74. Peng Y, Croce CM. The Role of microRNAs in Human Cancer. Signal Transduct Target Ther (2016) 1:15004. doi: 10.1038/sigtrans.2015.4

75. Breunig C, Pahl J, Küblbeck M, Miller M, Antonelli D, Erdem N, et al. MicroRNA-519a-3p Mediates Apoptosis Resistance in Breast Cancer Cells and Their Escape From Recognition by Natural Killer Cells. Cell Death Dis (2017) 8:e2973. doi: 10.1038/cddis.2017.364

76. Xie J, Liu M, Li Y, Nie Y, Mi Q, Zhao S. Ovarian Tumor-Associated microRNA-20a Decreases Natural Killer Cell Cytotoxicity by Downregulating MICA/B Expression. Cell Mol Immunol (2014) 11:495502. doi: $10.1038 / \mathrm{cmi} .2014 .30$

77. Grenda A, Krawczyk P. New Dancing Couple: PD-L1 and MicroRNA. Scand J Immunol (2017) 86:130-34. doi: 10.1111/sji.12577

78. Jasinski-Bergner S, Stoehr C, Bukur J, Massa C, Braun J, Hüttelmaier S, et al. Clinical Relevance of miR-Mediated HLA-G Regulation and the Associated Immune Cell Infiltration in Renal Cell Carcinoma. Oncoimmunology (2015) 4:e1008805. doi: 10.1080/2162402X.2015.1008805

79. Li J, Lin TY, Chen L, Liu Y, Dian MJ, Hao WC, et al. Mir-19 Regulates the Expression of Interferon-Induced Genes and Mhc Class I Genes in Human Cancer Cells. Int J Med Sci (2020) 17:953-64. doi: 10.7150/ijms.44377

80. Seeler JS, Dejean A. SUMO and the Robustness of Cancer. Nat Rev Cancer (2017) 17:184-97. doi: 10.1038/nrc.2016.143

81. Zitti B, Molfetta R, Fionda C, Quatrini L, Stabile H, Lecce M, et al. Innate Immune Activating Ligand SUMOylation Affects Tumor Cell Recognition by NK Cells. Sci Rep (2017) 7:10445. doi: 10.1038/s41598-017-10403-0

82. Thomas M, Boname JM, Field S, Nejentsev S, Salio M, Cerundolo V, et al. Down-Regulation of NKG2D and NKp80 Ligands by Kaposi's SarcomaAssociated Herpesvirus K5 Protects Against NK Cell Cytotoxicity. Proc Natl Acad Sci USA (2008) 105:1656-61. doi: 10.1073/pnas.0707883105

83. Oppenheim DE, Roberts SJ, Clarke SL, Filler R, Lewis JM, Tigelaar RE, et al. Sustained Localized Expression of Ligand for the Activating NKG2D 
Receptor Impairs Natural Cytotoxicity In Vivo and Reduces Tumor Immunosurveillance. Nat Immunol (2005) 6:928-37. doi: 10.1038/ni1239

84. Molfetta R, Quatrini L, Zitti B, Capuano C, Galandrini R, Santoni A, et al. Regulation of NKG2D Expression and Signaling by Endocytosis. Trends Immunol (2016) 37:790-802. doi: 10.1016/j.it.2016.08.015

85. Wensveen FM, Jelenčić V, Polić B. NKG2D: A Master Regulator of Immune Cell Responsiveness. Front Immunol (2018) 9:441. doi: 10.3389/ fimmu.2018.00441

86. Weiss T, Schneider H, Silginer M, Steinle A, Pruschy M, Polic B, et al. NKG2DDependent Antitumor Effects of Chemotherapy and Radiotherapy Against Glioblastoma. Clin Cancer Res (2018) 24:882-95. doi: 10.1158/10780432.CCR-17-1766

87. Luo D, Dong XW, Yan B, Liu M, Xue TH, Liu H, et al. MG132 Selectively Upregulates MICB Through the DNA Damage Response Pathway in A549 Cells. Mol Med Rep (2019) 24:882-95. doi: 10.3892/mmr.2018.9676

88. Pickup M, Novitskiy S, Moses HL. The Roles of Tgfß in the Tumour Microenvironment. Nat Rev Cancer (2013) 13:788-99. doi: 10.1038/nrc3603

89. Yan X, Xiong X, Chen YG. Feedback Regulation of TGF- $\beta$ Signaling. Acta Biochim Biophys Sin (Shanghai) (2018) 50:37-50. doi: 10.1093/abbs/gmx129

90. Foltz JA, Moseman JE, Thakkar A, Chakravarti N, Lee DA. Tgfß Imprinting During Activation Promotes Natural Killer Cell Cytokine Hypersecretion. Cancers (Basel) (2018) 10:423. doi: 10.3390/cancers10110423

91. Regis S, Caliendo F, Dondero A, Bellora F, Casu B, Bottino C, et al. Main NK Cell Receptors and Their Ligands: Regulation by microRNAs. AIMS Allergy Immunol (2018) 2:98-112. doi: 10.3934/allergy.2018.2.98

92. Yu J, Wei M, Becknell B, Trotta R, Liu S, Boyd Z, et al. Pro- and Antiinflammatory Cytokine Signaling: Reciprocal Antagonism Regulates Interferon-Gamma Production by Human Natural Killer Cells. Immunity (2006) 24:575-90. doi: 10.1016/j.immuni.2006.03.016

93. Zou Z, Tao T, Li H, Zhu X. MTOR Signaling Pathway and mTOR Inhibitors in Cancer: Progress and Challenges. Cell Biosci (2020). doi: 10.1186/s13578020-00396-1

94. Viel S, Besson L, Marotel M, Walzer T, Marçais A. Regulation of mTOR Metabolic Fitness and Effector Functions by Cytokines in Natural Killer Cells. Cancers (Basel) (2017) 10:31. doi: 10.3390/cancers9100132

95. Donnelly RP, Loftus RM, Keating SE, Liou KT, Biron CA, Gardiner CM, et al. Mtorc1-Dependent Metabolic Reprogramming Is a Prerequisite for NK Cell Effector Function. J Immunol (2014) 193:4477-84. doi: 10.4049/ jimmunol.1401558

96. Viel S, Marçais A, Guimaraes FSF, Loftus R, Rabilloud J, Grau M, et al. TGF$\beta$ Inhibits the Activation and Functions of NK Cells by Repressing the mTOR Pathway. Sci Signal (2016) 9:ra19. doi: 10.1126/scisignal.aad1884

97. Rozen-Zvi B, Hayashida T, Hubchak SC, Hanna C, Platanias LC, Schnaper HW. TGF- $\beta /$ Smad3 Activates Mammalian Target of Rapamycin Complex-1 to Promote Collagen Production by Increasing HIF-1 $\alpha$ Expression. Am J Physiol - Ren Physiol (2013) 305:F485-94. doi: 10.1152/ajprenal.00215.2013

98. Pietra G, Manzini C, Rivara S, Vitale M, Cantoni C, Petretto A, et al. Melanoma Cells Inhibit Natural Killer Cell Function by Modulating the Expression of Activating Receptors and Cytolytic Activity. Cancer Res (2012) 72:1407-15. doi: 10.1158/0008-5472.CAN-11-2544

99. Amo L, Tamayo-Orbegozo E, Maruri N, Buqué A, Solaun M, Riñón M, et al. Podocalyxin-Like Protein 1 Functions as an Immunomodulatory Molecule in Breast Cancer Cells. Cancer Lett (2015) 368:26-35. doi: 10.1016/ j.canlet.2015.06.029

100. Melaiu O, Lucarini V, Cifaldi L, Fruci D. Influence of the Tumor Microenvironment on NK Cell Function in Solid Tumors. Front Immunol (2020) 10:3038. doi: 10.3389/fimmu.2019.03038

101. Mosser DM, Edwards JP. Exploring the Full Spectrum of Macrophage Activation. Nat Rev Immunol (2008) 8:958-69. doi: 10.1038/nri2448

102. Roszer T. Understanding the Mysterious M2 Macrophage Through Activation Markers and Effector Mechanisms. Mediators Inflamm (2015) 2015:1-16. doi: 10.1155/2015/816460

103. Biswas SK, Allavena P, Mantovani A. Tumor-Associated Macrophages: Functional Diversity, Clinical Significance, and Open Questions. Semin Immunopathol (2013) 35:585-600. doi: 10.1007/s00281-013-0367-7

104. Zhang Q, Liu L, Gong C, Shi H, Zeng Y, Wang X, et al. Prognostic Significance of Tumor-Associated Macrophages in Solid Tumor: A Meta-Analysis of the Literature. PloS One (2012) 7:e50946. doi: 10.1371/journal.pone.0050946
105. Krneta T, Gillgrass A, Poznanski S, Chew M, Lee AJ, Kolb M, et al. M2Polarized and Tumor-Associated Macrophages Alter NK Cell Phenotype and Function in a Contact-Dependent Manner. J Leukoc Biol (2017) 101:285-95. doi: 10.1189/jlb.3a1215-552r

106. Peng LS, Zhang JY, Teng YS, Zhao YL, Wang TT, Mao FY, et al. TumorAssociated Monocytes/Macrophages Impair NK-Cell Function via Tgf $\beta 1$ in Human Gastric Cancer. Cancer Immunol Res (2017) 5:248-56. doi: 10.1158/ 2326-6066.CIR-16-0152

107. Choo QWW, Koean RAG, Chang SC, Chng WJ, Chan MC, Wang W, et al. Macrophages Protect Mycoplasma-Infected Chronic Myeloid Leukemia Cells From Natural Killer Cell Killing. Immunol Cell Biol (2020) 98:13851. doi: 10.1111/imcb.12309

108. Srpan K, Ambrose A, Karampatzakis A, Saeed M, Cartwright ANR, Guldevall K, et al. Shedding of CD16 Disassembles the NK Cell Immune Synapse and Boosts Serial Engagement of Target Cells. J Cell Biol (2018) 217:3267-83. doi: 10.1083/jcb.201712085

109. Capuano C, Pighi C, Battella S, De Federicis D, Galandrini R, Palmieri G. Harnessing Cd16-Mediated Nk Cell Functions to Enhance Therapeutic Efficacy of Tumor-Targeting Mabs. Cancers (Basel) (2021) 13:2500. doi: $10.3390 /$ cancers 13102500

110. Pahl JHW, Koch J, Gotz JJ, Arnold A, Reusch U, Gantke T, et al. Cd16a Activation of Nk Cells Promotes Nk Cell Proliferation and Memory-Like Cytotoxicity Against Cancer Cells. Cancer Immunol Res (2018) 6:517-27. doi: 10.1158/2326-6066.CIR-17-0550

111. Gabrilovich DI, Nagaraj S. Myeloid-Derived Suppressor Cells as Regulators of the Immune System. Nat Rev Immunol (2009) 9:162-74. doi: 10.1038/ nri2506

112. Li H, Han Y, Guo Q, Zhang M, Cao X. Cancer-Expanded Myeloid-Derived Suppressor Cells Induce Anergy of NK Cells Through Membrane-Bound TGF-ß1. J Immunol (2009) 182:240-9. doi: 10.4049/jimmunol.182.1.240

113. Liu C, Yu S, Kappes J, Wang J, Grizzle WE, Zinn KR, et al. Expansion of Spleen Myeloid Suppressor Cells Represses NK Cell Cytotoxicity in Tumor-Bearing Host. Blood (2007) 109:4336-42. doi: 10.1182/blood-2006-09-046201

114. Hoechst B, Voigtlaender T, Ormandy L, Gamrekelashvili J, Zhao F, Wedemeyer H, et al. Myeloid Derived Suppressor Cells Inhibit Natural Killer Cells in Patients With Hepatocellular Carcinoma via the NKp30 Receptor. Hepatology (2009). doi: 10.1002/hep.23054

115. Nausch N, Galani IE, Schlecker E, Cerwenka A. Mononuclear MyeloidDerived "Suppressor" Cells Express RAE-1 and Activate Natural Killer Cells. Blood (2008) 112:4080-89. doi: 10.1182/blood-2008-03-143776

116. Saleh R, Elkord E. FoxP3+ T Regulatory Cells in Cancer: Prognostic Biomarkers and Therapeutic Targets. Cancer Lett (2020) 490:174-85. doi: 10.1016/j.canlet.2020.07.022

117. Kondělková K, Vokurková D, Krejsek J, Borská L, Fiala Z, Ctirad A. Regulatory $\mathrm{T}$ Cells (TREG) and Their Roles in Immune System With Respect to Immunopathological Disorders. Acta Med (Hradec Kralove) (2010) 53:73-7. doi: 10.14712/18059694.2016.63

118. Pedroza-Pacheco I, Madrigal A, Saudemont A. Interaction Between Natural Killer Cells and Regulatory T Cells: Perspectives for Immunotherapy. Cell Mol Immunol (2013) 10:222-29. doi: 10.1038/cmi.2013.2

119. Gasteiger G, Hemmers S, Firth MA, Le Floc'h A, Huse M, Sun JC, et al. IL-2Dependent Tuning of NK Cell Sensitivity for Target Cells is Controlled by Regulatory T Cells. J Exp Med (2013) 210:1065-68. doi: 10.1084/jem.20122462

120. Ghiringhelli F, Ménard C, Terme M, Flament C, Taieb J, Chaput N, et al. CD4+CD25+ Regulatory T Cells Inhibit Natural Killer Cell Functions in a Transforming Growth Factor- $\beta$-Dependent Manner. J Exp Med (2005) 202:1075-85. doi: 10.1084/jem.20051511

121. Smyth MJ, Teng MWL, Swann J, Kyparissoudis K, Godfrey DI, Hayakawa Y. $\mathrm{CD} 4+\mathrm{CD} 25+\mathrm{T}$ Regulatory Cells Suppress NK Cell-Mediated Immunotherapy of Cancer. J Immunol (2006) 176:1582-87. doi: 10.4049/jimmunol.176.3.1582

122. Huong PT, Nguyen LT, Nguyen XB, Lee SK, Bach DH. The Role of Platelets in the Tumor-Microenvironment and the Drug Resistance of Cancer Cells. Cancers (Basel) (2019) 11:240. doi: 10.3390/cancers 11020240

123. Nieswandt B, Hafner M, Echtenacher B, Männel DN. Lysis of Tumor Cells by Natural Killer Cells in Mice is Impeded by Platelets. Cancer Res (1999) 59:1295-300.

124. Du Y, Liu X, Guo SW. Platelets Impair Natural Killer Cell Reactivity and Function in Endometriosis Through Multiple Mechanisms. Hum Reprod (2017) 32:794-810. doi: 10.1093/humrep/dex014 
125. Cluxton CD, Spillane C, O'Toole SA, Sheils O, Gardiner CM, O'Leary JJ. Suppression of Natural Killer Cell NKG2D and CD226 Anti-Tumour Cascades by Platelet Cloaked Cancer Cells: Implications for the Metastatic Cascade. PloS One (2019) 14:e0211538. doi: 10.1371/journal.pone.0211538

126. Jinushi M, Takehara T, Tatsumi T, Hiramatsu N, Sakamori R, Yamaguchi S, et al. Impairment of Natural Killer Cell and Dendritic Cell Functions by the Soluble Form of MHC Class I-Related Chain A in Advanced Human Hepatocellular Carcinomas. J Hepatol (2005) 43:1013-20. doi: 10.1016/ j.jhep.2005.05.026

127. Placke T, Örgel M, Schaller M, Jung G, Rammensee HG, Kopp HG, et al. Platelet-Derived MHC Class I Confers a Pseudonormal Phenotype to Cancer Cells That Subverts the Antitumor Reactivity of Natural Killer Immune Cells. Cancer Res (2012) 72:440-8. doi: 10.1158/0008-5472.CAN-11-1872

128. Semple JW, Italiano JE, Freedman J. Platelets and the Immune Continuum. Nat Rev Immunol (2011) 11:264-74. doi: 10.1038/nri2956

129. Huse M. Microtubule-Organizing Center Polarity and the Immunological Synapse: Protein Kinase C and Beyond. Front Immunol (2012) 3:235. doi: $10.3389 /$ fimmu.2012.00235

130. Chen X, Trivedi PP, Ge B, Krzewski K, Strominger JL. Many NK Cell Receptors Activate ERK2 and JNK1 to Trigger Microtubule Organizing Center and Granule Polarization and Cytotoxicity. Proc Natl Acad Sci USA (2007) 104:6329-34. doi: 10.1073/pnas.0611655104

131. Bryceson YT, March ME, Barber DF, Ljunggren HG, Long EO. Cytolytic Granule Polarization and Degranulation Controlled by Different Receptors in Resting NK Cells. J Exp Med (2005) 202:1001-12. doi: 10.1084/ jem. 20051143

132. Yu JA, Sadaria MR, Meng X, Mitra S, Ao L, Fullerton DA, et al. Lung Cancer Cell Invasion and Expression of Intercellular Adhesion Molecule-1 (ICAM1) are Attenuated by Secretory Phospholipase A 2 Inhibition. J Thorac Cardiovasc Surg (2012) 143:405-11. doi: 10.1016/j.jtcvs.2011.10.026

133. Di D, Chen L, Wang L, Sun P, Liu Y, Xu Z, et al. Downregulation of Human Intercellular Adhesion Molecule-1 Attenuates the Metastatic Ability in Human Breast Cancer Cell Lines. Oncol Rep (2016) 35:1541-48. doi: 10.3892/ or.2016.4543

134. Quann EJ, Liu X, Altan-Bonnet G, Huse M. A Cascade of Protein Kinase C Isozymes Promotes Cytoskeletal Polarization in T Cells. Nat Immunol (2011) 12:647-54. doi: 10.1038/ni.2033

135. Ben-Shmuel A, Sabag B, Biber G, Barda-Saad M. The Role of the Cytoskeleton in Regulating the Natural Killer Cell Immune Response in Health and Disease: From Signaling Dynamics to Function. Front Cell Dev Biol (2021) 9:609532. doi: 10.3389/fcell.2021.609532

136. Eitler J, Wotschel N, Miller N, Boissel L, Klingemann HG, Wels W, et al. Inability of Granule Polarization by NK Cells Defines Tumor Resistance and can be Overcome by CAR or ADCC Mediated Targeting. I Immunother Cancer (2021) 9:e001334. doi: 10.1136/jitc-2020-001334

137. Matalon O, Ben-Shmuel A, Kivelevitz J, Sabag B, Fried S, Joseph N, et al. Actin Retrograde Flow Controls Natural Killer Cell Response by Regulating the Conformation State of SHP -1. EMBO J (2018) 37:e9626. doi: 10.15252/ embj.201696264

138. Orange JS, Ramesh N, Remold-O’Donnell E, Sasahara Y, Koopman L, Byrne M, et al. Wiskott-Aldrich Syndrome Protein is Required for NK Cell Cytotoxicity and Colocalizes With Actin to NK Cell-Activating Immunologic Synapses. Proc Natl Acad Sci USA (2002) 99:11351-56. doi: 10.1073/ pnas. 162376099

139. Butler B, Cooper JA. Distinct Roles for the Actin Nucleators Arp2/3 and Hdial During NK-Mediated Cytotoxicity. Curr Biol (2009) 19:1886-96. doi: 10.1016/j.cub.2009.10.029

140. Wülfing C, Purtic B, Klem J, Schatzle JD. Stepwise Cytoskeletal Polarization as a Series of Checkpoints in Innate But Not Adaptive Cytolytic Killing. Proc Natl Acad Sci USA (2003) 100:7767-72. doi: 10.1073/pnas.1336920100

141. Carisey AF, Mace EM, Saeed MB, Davis DM, Orange JS. Nanoscale Dynamism of Actin Enables Secretory Function in Cytolytic Cells. Curr Biol (2018) 28:489-502.e9. doi: 10.1016/j.cub.2017.12.044

142. Mace EM, Orange JS. Lytic Immune Synapse Function Requires Filamentous Actin Deconstruction by Coronin 1a. Proc Natl Acad Sci USA (2014) 111:6708-13. doi: 10.1073/pnas.1314975111
143. Andzelm MM, Chen X, Krzewski K, Orange JS, Strominger JL. Myosin IIA Is Required for Cytolytic Granule Exocytosis in Human NK Cells. J Exp Med (2007) 204:2285-291. doi: 10.1084/jem.20071143

144. Wilton KM, Overlee BL, Billadeau DD. NKG2D-DAP10 Signaling Recruits EVL to the Cytotoxic Synapse to Generate F-Actin and Promote NK Cell Cytotoxicity. J Cell Sci (2019) 133. doi: 10.1242/jcs.230508

145. Kirby TJ, Lammerding J. Emerging Views of the Nucleus as a Cellular Mechanosensor. Nat Cell Biol (2018) 20:373-81. doi: 10.1038/s41556-018-0038-y

146. Elosegui-Artola A, Andreu I, Beedle AEM, Lezamiz A, Uroz M, Kosmalska AJ, et al. Force Triggers YAP Nuclear Entry by Regulating Transport Across Nuclear Pores. Cell (2017) 171:1397-410.e14. doi: 10.1016/j.cell.2017.10.008

147. Burgdorf S, Porubsky S, Marx A, Popovic ZV. Cancer Acidity and Hypertonicity Contribute to Dysfunction of Tumor-Associated Dendritic Cells: Potential Impact on Antigen Cross-Presentation Machinery. Cancers (Basel) (2020) 12:1-13. doi: 10.3390/cancers12092403

148. Al Absi A, Wurzer H, Guerin C, Hoffmann C, Moreau F, Mao X, et al. Actin Cytoskeleton Remodeling Drives Breast Cancer Cell Escape From Natural KillerMediated Cytotoxicity. Cancer Res (2018) 78:5631-43. doi: 10.1158/00085472.CAN-18-0441

149. Henley MJ, Koehler AN. Advances in Targeting 'Undruggable' Transcription Factors With Small Molecules. Nat Rev Drug Discov (2021) 20:669-88. doi: 10.1038/s41573-021-00199-0

150. Marofi F, Rahman HS, Thangavelu L, Dorofeev A, Bayas-Morejón F, Shirafkan N, et al. Renaissance of Armored Immune Effector Cells, CARNK Cells, Brings the Higher Hope for Successful Cancer Therapy. Stem Cell Res Ther (2021). doi: 10.1186/s13287-021-02251-7

151. Basar R, Daher M, Rezvani K. Next-Generation Cell Therapies: The Emerging Role of CAR-NK Cells. Blood Adv (2020) 12:200. doi: 10.1182/ bloodadvances.2020002547

152. Kim KS, Kim DH, Kim DH. Recent Advances to Augment NK Cell Cancer Immunotherapy Using Nanoparticles. Pharmaceutics (2021) 13:525. doi: 10.3390/pharmaceutics13040525

153. Marin-Acevedo JA, Kimbrough EMO, Lou Y. Next Generation of Immune Checkpoint Inhibitors and Beyond. J Hematol Oncol (2021) 14:45. doi: 10.1186/s13045-021-01056-8

154. Horowitz A, Strauss-Albee DM, Leipold M, Kubo J, Nemat-Gorgani N, Dogan OC, et al. Genetic and Environmental Determinants of Human NK Cell Diversity Revealed by Mass Cytometry. Sci Transl Med (2013) 5:208ra145. doi: $10.1126 /$ scitranslmed.3006702

155. Shih HY, Sciumè G, Mikami Y, Guo L, Sun HW, Brooks SR, et al. Developmental Acquisition of Regulomes Underlies Innate Lymphoid Cell Functionality. Cell (2016) 165:1120-133. doi: 10.1016/j.cell.2016.04.029

156. Yamamoto Y, Miyazato K, Takahashi K, Yoshimura N, Tahara H, Hayakawa Y. Lung-Resident Natural Killer Cells Control Pulmonary Tumor Growth in Mice. Cancer Sci (2018) 109:2670-676. doi: 10.1111/cas.13703

157. Parodi M, Favoreel H, Candiano G, Gaggero S, Sivori S, Mingari MC. NKp44-NKp44 Ligand Interactions in the Regulation of Natural Killer Cells and Other Innate Lymphoid Cells in Humans. Front Immunol (2019) 10:719. doi: 10.3389/fimmu.2019.00719

Conflict of Interest: The authors declare that the research was conducted in the absence of any commercial or financial relationships that could be construed as a potential conflict of interest.

Publisher's Note: All claims expressed in this article are solely those of the authors and do not necessarily represent those of their affiliated organizations, or those of the publisher, the editors and the reviewers. Any product that may be evaluated in this article, or claim that may be made by its manufacturer, is not guaranteed or endorsed by the publisher.

Copyright $\odot 2021$ Lee, Wong and Ding. This is an open-access article distributed under the terms of the Creative Commons Attribution License (CC BY). The use, distribution or reproduction in other forums is permitted, provided the original author(s) and the copyright owner(s) are credited and that the original publication in this journal is cited, in accordance with accepted academic practice. No use, distribution or reproduction is permitted which does not comply with these terms. 